\title{
An Approach for Switched Reluctance Generator in a Wind Generation System With a Wide Range of Operation Speed
}

\author{
Tárcio André dos Santos Barros, Member, IEEE, Pedro José dos Santos Neto, Student Member, IEEE, \\ Paulo Sergio Nascimento Filho, Adson Bezerra Moreira, Member, IEEE, and Ernesto Ruppert Filho, Member, IEEE
}

\begin{abstract}
This paper presents a complete approach for switched reluctance generator (SRG) in variable wind energy conversion systems. Two forms of direct power control (DPC) and a commutative system that allows SRG performance at a wide range of speed variations are proposed. Thus, more mechanical energy can be captured in wind generation. In the proposed structure, the SRG operates in a self-excited mode using a common dc bus system of a voltage source inverter connected to an electrical grid. DPCs are proposed by hysteresis of the SRG phase current for low-speed operation (DPC-LS) and by a single pulse of current for high-speed operation (DPC-HS). The low-pass filter employed to obtain the average power generated may slow down the response of the control system of the DPC applied to SRG. To improve the system performance, sliding mode controllers in DPCs were used. For operation throughout a wide speed range, the DPC-LS and DPC-HS controls should be joined. Therefore, a commutative system with smooth transition between DPC modes is proposed. Finally, simulations and experimental tests were conducted to verify the behavior of the proposed arrangement. The results confirmed correct operation of the proposed system.
\end{abstract}

Index Terms-Direct power controls (DPCs), sliding mode (SM) controllers, switched reluctance generators (SRG), variable speed operation, wind energy.

\section{INTRODUCTION}

$\mathbf{T}$ HE switched reluctance generator (SRG) has been suggested as a good alternative for applications in wind power

Manuscript received October 27, 2016; revised December 4, 2016 and February 6, 2017; accepted April 15, 2017. Date of publication April 25, 2017; date of current version June 23, 2017. This work was supported in part by the São Paulo Research Foundation, FAPESP, under Grants 12/04872-0, 12/08911-0, and 15/12861-6. Recommended for publication by Associate Editor P. Bauer. (Corresponding author: Tárcio André dos Santos Barros.)

T. A. dos Santos Barros, P. J. dos Santos Neto, P. S. N. Filho, and E. R. Filho are with the Universidade Estadual de Campinas, Campinas 13084-583, Brazil (e-mail: tarcioandre@hotmail.com; pedrojsn@dsce.fee.unicamp.br; paulosnf@dsce.fee.unicamp.br; ruppert@fee.unicamp.br).

A. B. Moreira is with the Federal University of Ceará, Fortaleza 60020-180, Brazil (e-mail: adsonbm@gmail.com).

This paper has supplementary downloadable multimedia material available at http://ieeexplore.ieee.org provided by the authors. The material consists of a video showing the experiment in real-time; detailed block diagrams of the systems, wiring diagrams; data and SRG model for Simulink-MATLAB simulation; PCB design and Gerber files of the AHB developed. The provision of these files allows the readers to easily build up the converter for experimental applications. This material is $49.2 \mathrm{MB}$ in size.

Color versions of one or more of the figures in this paper are available online at http://ieeexplore.ieee.org.

Digital Object Identifier 10.1109/TPEL.2017.2697822 generation because it operates over a wide range of speeds at a high performance level [1], [2]. Moreover, the SRG has attractive features, such as its mechanical robustness, high performance, low manufacturing cost, and an absence of permanent magnetic elements [2]-[7]. The main obstacles to the industrial use of the SRG are torque ripple, audible noise, the need for position sensors, the need for robust controls for a wide range of speeds, and the lack of methodologies for its electromagnetic design. A considerable amount of effort has been invested in mitigating these obstacles as in [4], [8]-[10].

The majority of the current works has approached SRG electromagnetic project. In [11], a high-efficiency small SRG, applied to variable speed wind generation, was projected and built using finite-element techniques. Building a prototype have confirmed the efficiency of the studied SRG. The analysis of projects and configurations using different number of poles were performed by [12]-[15]. In [16], a $10 \mathrm{~kW}$ SRG-C was built to operate in wind systems without using a gearbox. In [17], an axial reluctance generator was projected to operate at low speed. A complementary excitation winding was incorporated to a C-core SRG to increase the generated power [18].

The strategy adopted to control an SRG is directly related to the operating speed and application [19]. The bus voltage control is important for applications in electric vehicles and aircraft in which the dc bus voltage needs to be maintained at a constant value [2], [19]-[22]. This type of control has also been studied for wind power generation in isolated systems or dc microgrid.

For applications in wind power generation, where the objective is to generate the maximum possible energy, the SRG must operate at variable speed and power control should be used to capture all the energy provided by the wind turbine. Studies that addressed this type of control are discussed next.

In [23], a speed control system with maximum power point tracking for SRG was simulated. Park and Chen [24] demonstrated a speed control system for SRGs applied in wind power generation systems. A self-adjusting fuzzy controller controls the SRG speed-acting reference of the SRG current. Controllers for SRGs operating at low speed have also been developed [25], [26]. In [27], an innovative control strategy of SRG, operating in continuous-conduction mode, was implemented for a wind power plant application. First, the procedure for determination 


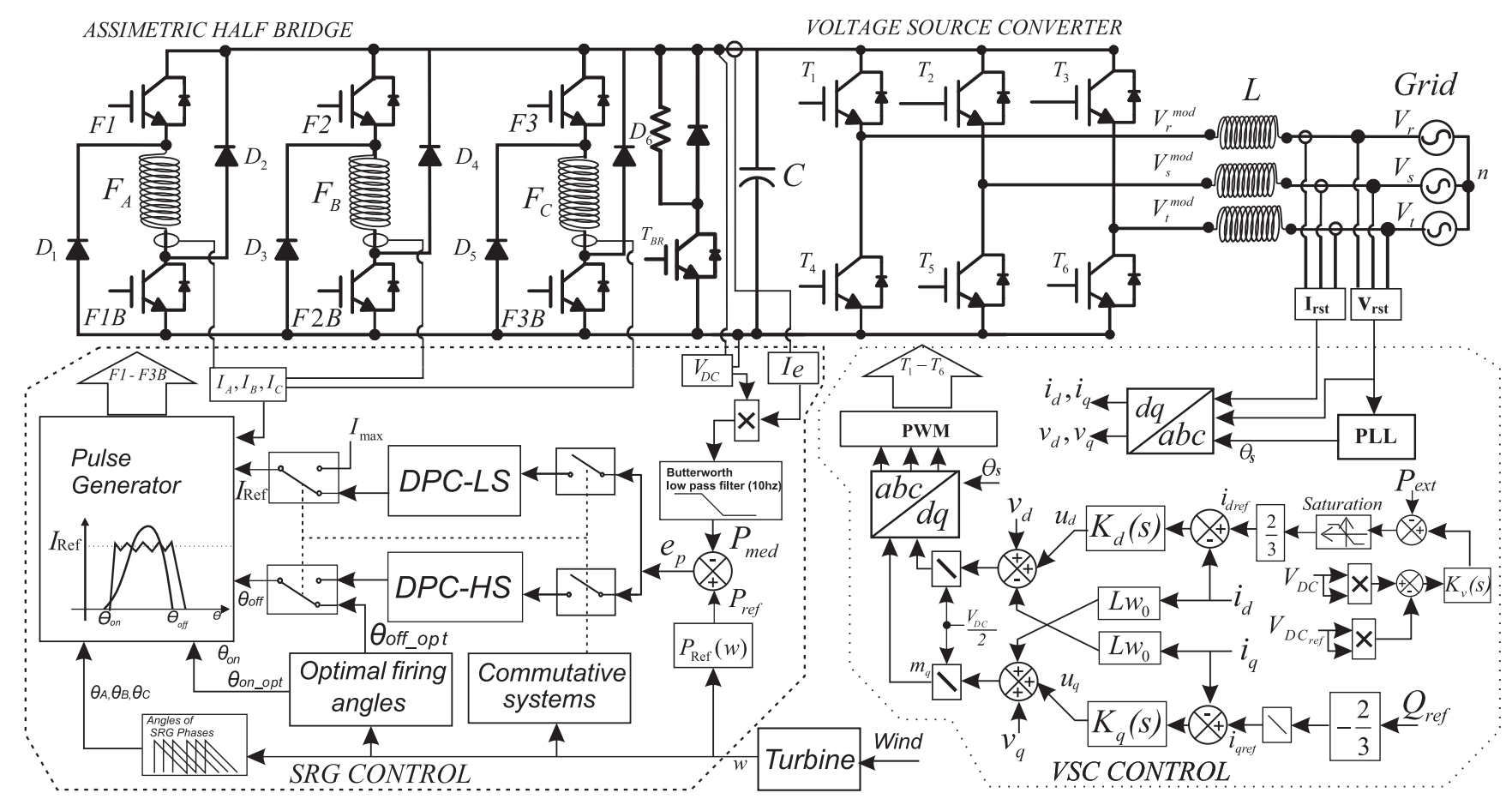

Fig. 1. Proposed structure of the SRG in a wind generation system connected to the electrical grid.

of the optimal control parameters as a function of rotor speed that provides the maximal output power of SRG was described. Thereafter, the control angles versus speed dependence were linearized to be used for control of SRM in the wind turbine generator system (WTGS). The output power of the WTGS was simply controlled by controlling the dc supply voltage of SRM. In these studies, the generation system was not connected to an electrical grid and only the simulation results were presented.

Some articles discuss the connection of an SRG to the electrical grid in wind power generation systems that have variable speed. In [28] and [29], simulations of a speed-control system were performed using an adaptive neural network acting on the current control of an SRG connected to an electrical grid by means of a voltage source converter (VSC). McSwiggan et al. [30] examined a similar current control system and a system was added for keeping the dc-link voltage constant when a fault occurred in the electrical grid. However, the results were satisfactory only for low operating speeds and only simulations were performed in these studies.

In our literature survey, few experimental studies that addressed the SRG connection to an electrical grid were found. In [1], a control system for SRGs applied in wind power generation was presented. A current controller adjusted the power generated by the SRG. Experiments showed high system efficiency for a wide range of variable speeds. However, the control, which used pulse width modulation (PWM) in situations where the speed varies in a wide range, was contested by Sawata [19] because of its hardware complexity and increased losses. In addition, the system was connected to the electrical grid through a VSC and had a buck converter between the inverter connected to the electrical grid and the SRG, as the SRG used was designed to operate with a voltage lower than the dc link. In [31]-[33], a single-phase inverter connected to an SRG with dependent electrical grid excitement was used.

In these studies, however, neither direct power control (DPC) nor optimization system for the SRG operating points were used. Therefore, the parameter settings for activation of the SRG were adjusted randomly. Furthermore, there seems to be no methodology for determining the activation mode of an SRG depending on the operating speed.

In this paper, an approach for SRG operation in variable wind generation systems with a wide speed range is proposed. Fig. 1 shows the complete systems proposed. In the proposed structure, the SRG operates in a self-excited mode using a common dc bus system of a VSC connected to an electrical grid. Thus, the need for additional converters and excitation sources for magnetization of the SRG is eliminated. An approach to determine the modes of SRG activation is presented. Two forms of DPC for SRGs were used: DPC by hysteresis for low-speed operation and by a single pulse of current for high-speed operation. A commutative system of DPCs is proposed, which allows the SRG to operate at a wide range of speed variations. DPCs were first developed using proportional integral (PI) controllers and, to improve system performance, sliding mode (SM) controllers were used. Furthermore, the optimal activating parameters are adjusted according to the operating speed and control mode.

\section{Generation System USED IN THE StUdY}

The wind turbine mechanical power is given by

$$
P_{T}=\frac{1}{2} \pi R^{2} \rho C_{p}(\lambda, \beta) v^{3}
$$




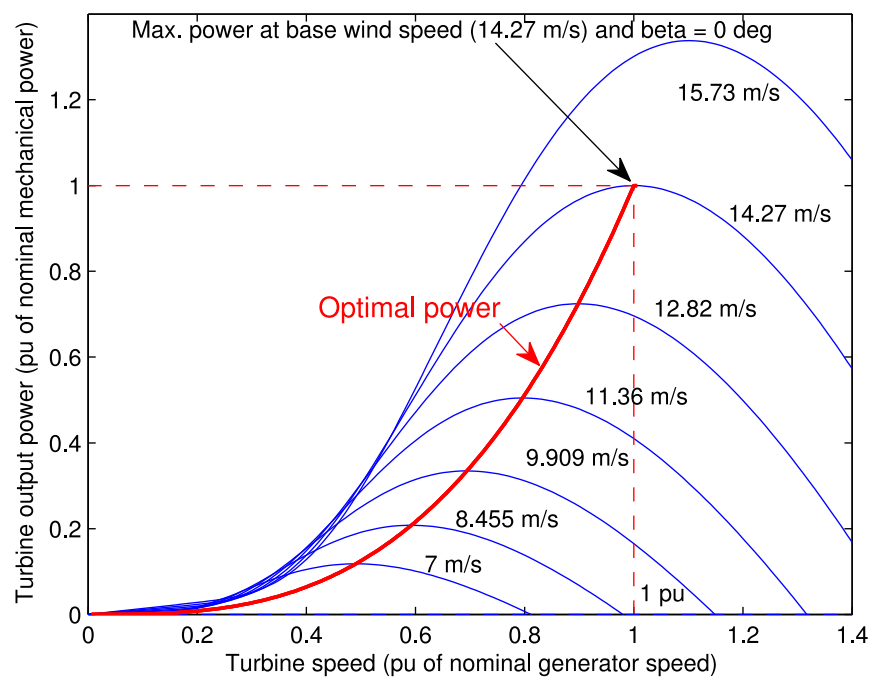

Fig. 2. Optimal power for the wind system studied.

where $R$ is the rotor radius, $\rho$ is the air density, $C_{p}(\lambda, \beta)$ is the turbine power coefficient, $\lambda$ is the tip speed ratio, $\beta$ is the pitch angle, and $v$ is the wind speed. When the wind is below the rated speed, the system operation at variable speeds increases the energy generation efficiency [1]. When the wind speed is lower than the nominal speed, the generator torque is calculated to obtain the maximum aerodynamic efficiency the turbine. The optimizing profile of the generated output power for variable speeds can be expressed by

$$
P_{\mathrm{opt}}=k_{\mathrm{opt}} w_{r}^{3}
$$

where $P_{\mathrm{opt}}$ is the required optimal output power, $k_{\mathrm{opt}}$ is a constant that depends on the blade aerodynamics, turbine parameters, and gearbox of the wind turbine, and $w_{r}$ is the rotational speed.

The prototype of the wind generation system employs a $2 \mathrm{~kW}$ three-phase SRG, which has 12 salient poles on the stator and 8 salient poles on the rotor (12/8) (see appendix), with rated speed of operation equal to $157 \mathrm{rad} / \mathrm{s}(1500 \mathrm{r} / \mathrm{m})$. Thus, a value of $k_{\text {opt }}$ was adopted so that at the nominal speed the wind turbine presents the rated power of the SRG. Therefore, it is possible to calculate the profile of the optimal power generation for the system being studied (see Fig. 2). The power reference is equal to $2 \mathrm{~kW}$ for speeds greater than rated speed. In this mode, the angular speed is a closed loop controlled by adjusting the pitch angle. For wind speeds greater than a predefined maximum speed, the wind turbine shuts down in an orderly fashion for safety purposes.

The structure of the wind power generation system, with the SRG connected to an electrical grid, proposed in this paper (see Fig. 1) is based on the separate control of two power electronic converters.

The converter used to activate the SRG is an asymmetric half-bridge (AHB) converter. It is connected via the dc link to a VSC, which is connected to the electrical grid. The SRG control should regulate the extraction of the maximum electric power according to the wind profile of the system. The VSC control is

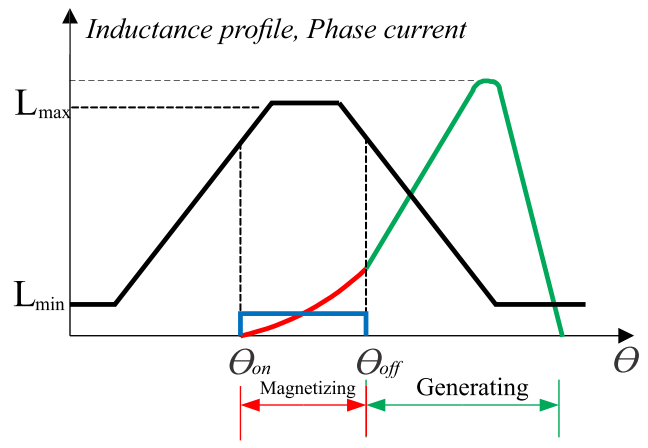

Fig. 3. Excitation and generation stage in one SRG phase.

responsible for regulating the dc-link voltage $V_{\mathrm{DC}}$ and sending the power generated by the SRG to the electrical grid, in addition to controlling the power factor of the energy sent to the grid. In other works [31], [34] the $V_{\mathrm{DC}}$ regulation is performed by the SRG control, and the generated power is regulated by the VSC.

Stability problems in a self-excited mode usually occurs when the load is directly connected to the dc bus and whenever the dc bus voltage is regulated by the SRG control. Instability may occur because the energy generated by the SRG is used to keep the voltage $V_{\mathrm{DC}}$ under control to supply the energy sent to the load and the SRG phase excitation. If the load demands a high power, the energy stored in the dc bus capacitor may not be sufficient to excite the SRG phases, which may reduce the energy generated and, consequently, the dc bus voltage will tend to become unstable [2], [35]. Nevertheless, in the proposed systems, $V_{\mathrm{DC}}$ is controlled by the VSC control. Initially, the VSC control loads the dc bus voltage through the electrical grid, and then the SRG power control is activated. In this case, stability problems are not a concern because if the SRG requires high energy in the magnetization step, the VSC control acts in order to keep the energy in the dc bus capacitor constant.

\section{SRG OPERATION}

A switched reluctance machine operates as a generator if each phase is excited when the phase inductance is decreasing. Hence, if $L(\theta)$ is the angle-dependent phase inductance, the excitation must occur when $d L(\theta) / d t<0$, as shown in Fig. 3 . Many converter topologies can be employed to achieve this goal [1]-[3].

The AHB converter is extensively used because of its robustness and simplicity of control. This converter provides unidirectional phase currents and drives each phase independently. Each converter phase consists of two transistors and two freewheeling diodes in order to allow energy recovery to the dc bus. Moreover, the AHB allows energy regeneration stage and freewheeling technique when necessary [36].

To operate as a generator, two steps of the converter are required for each phase of the machine: excitation and generation (see Fig. 3). During the excitation step, one of the SRG phases is submitted to the excitation voltage and current flows through its winding. The turn-on angle $\theta_{\text {on }}$ is defined as the rotor angle in which magnetization starts. At each excitation period, energy 


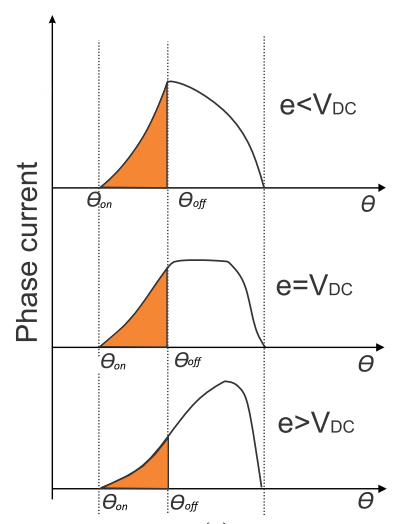

(a)

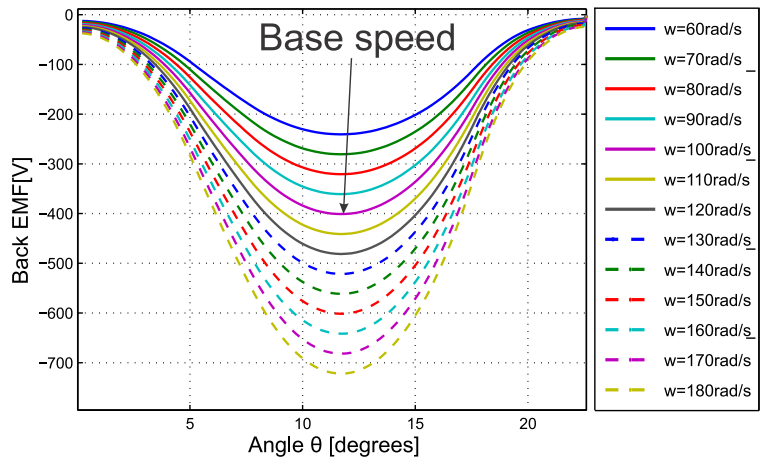

(b)

Fig. 4. (a) Types of waveforms from the SRG currents. (b) Back electromotive force estimated.

is sent to the magnetic field of the corresponding phase. During the generation step, the energy flows to the load in addition to the resulting mechanical-to-electrical conversion. The turn-off angle $\theta_{\text {off }}$ defines the rotor angle in which the generation step begins.

\section{A. Defining the Activation Modes of the SRG}

The proposed methods for activating the system according to the SRG operating speed are discussed below.

Neglecting resistive voltage drop on the SRG windings, then the phase current, when the excitation stage is terminated, depends on the phase voltage $v$ and the back electromagnetic force (EMF) $e$, as shown in (3). Thus, the electric current can take three forms, as shown in Fig. 4(a)

$$
v-e=L(\theta) \frac{\partial i}{\partial t}
$$

In the case where $e<V_{\mathrm{DC}}$, the current decreases after the excitation period. This occurs when the operating speed is reduced, since the Electromotive force decreases. When $V_{\mathrm{DC}}=e$, the electric current tends to remain constant after the excitation period. At higher speeds, $e>V_{\mathrm{DC}}$, the electric current tends to increase after the excitation period. In the case where $V_{\mathrm{DC}}<v$, the exciting factor $\varepsilon$ is larger. In general, $\varepsilon=0.3-0.4$ is considered acceptable. Higher values of $\varepsilon$ decrease efficiency, because much energy flow is required to magnetize the SRG [19], [37].

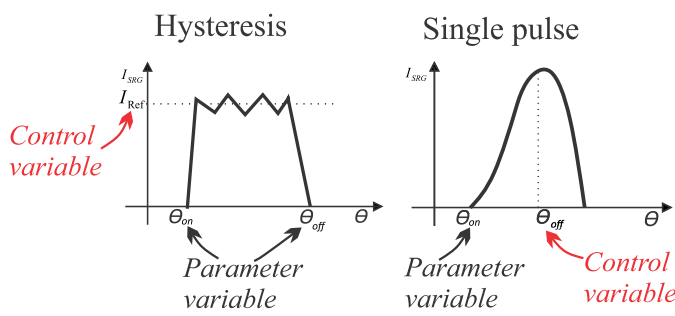

Fig. 5. Variable of hysteresis and single pulse activation.

When the current generated is lower than the maximum peak current, which is limited by the system, it is recommended that the current should be controlled in such a manner that $e>V_{\mathrm{DC}}$. If the current reaches high values, the voltage $V_{\mathrm{DC}}$ must be increased so that it approximates $e$. In a low-speed operation, $e$ decreases and single pulse operation should be avoided. In this case, current control by hysteresis or PWM may be used, as in [1], [3], [19].

To determine the SRG's operating mode, the operation base speed was estimated. By considering a constant current when activating the SRG, one can estimate the back EMF by

$$
e=i * w \frac{\partial L(\theta, i)}{\partial \theta} .
$$

The voltage $V_{\mathrm{DC}}$ is defined as $400 \mathrm{~V}$; this value allows the energy to flow through a voltage-sourced converter for a threephase $220 \mathrm{~V}$ electrical grid. The SRG's base speed $w_{s b}$ is defined as the speed at which $e=V_{\mathrm{DC}}$ [38]. The estimated value of $w_{s b}$ was $100 \mathrm{rad} / \mathrm{s}$ [see Fig. 4(b)].

To improve the SRG performance, it is proposed this activation should be performed in two modes. For low operating speeds $\left(w<w_{b}\right)$, SRG activation should be performed by current hysteresis, and for high speeds $\left(w>w_{b}\right)$, the activation should be performed by single pulse. Therefore

$$
\left\{\begin{array}{l}
\text { for }: w<100 \mathrm{rad} \Rightarrow \text { hysteresis of current } \\
\text { for }: w>100 \mathrm{rad} \Rightarrow \text { single pulse. }
\end{array}\right.
$$

For activation through hysteresis, the power control system is based on the adjustment of the reference current $I_{\text {ref }}$; this is the case the firing angles $\theta_{\text {on }}$ and $\theta_{\text {off }}$ are drive's parameters (see Fig. 5). For high speeds, the power control is realized by varying the turn-off angle $\theta_{\text {off }}$ and firing angle $\theta_{\text {on }}$ is drive's parameter.

High EMF values can cause high currents in SRG. However, using the activating parameters, which were obtained throughout optimization algorithms, high EMF situations are avoided. The angle $\theta_{\text {off }}$ has its maximum value limited, avoiding that the single pulse control leads the system to operate with high EMF. Furthermore, the system is endued with overcurrent protection. If an overcurrent occurs, the converters AHB and VSC will be disconnected automatically and a resistance is activated by means of a brake circuit at the dc bus to flow the energy.

\section{OPTIMAL FIRING ANGLES}

To obtain an analytical expression of the generated power is not an easy task because of the switching and the nonlinear nature of the electric current produced by an SRG [39]. Some 
simplifications should be performed to facilitate the understanding of the variables behavior versus the power generated by the SRG. The average output power of the SRG, not taking into consideration the losses discussed in [39], can be calculated by

$$
\begin{aligned}
P_{\mathrm{out}}= & \frac{N_{s} N_{r} V_{\mathrm{DC}}^{2}}{w}\left(\int_{\theta_{\mathrm{on}}}^{\theta} \frac{\left(\theta-\theta_{\mathrm{on}}\right)}{L(\theta)} d \theta\right. \\
& \left.+\int_{\theta_{\text {on }}}^{\theta} \frac{\left(\theta_{\mathrm{off}}-\theta-\theta_{\mathrm{on}}\right)}{L(\theta)} d \theta\right)
\end{aligned}
$$

where $N_{s}$ and $N_{r}$ are the number of poles of the stator and the rotor, respectively, $\theta$ is the angular position of the rotor, and $w$ is the mechanical speed.

By (5), it is verified that the output power is directly influenced by the firing angles, the dc-link voltage, and operation speed. The same output power can be generated with different combinations of these driver variables. However, these variables affect directly the electric and magnetic losses, as well as the torque ripples. Thus, it is fundamentally relevant to define the optimal values of the activation variables so that they can be adjusted such that the SRG operates satisfactorily in a wide speed range.

In the proposed system, the dc voltage is constant. Then, the power generated by the SRG can be reached using different combinations of firing angles, hysteresis current (at low speeds), and speed.

Thus, knowing the operation points of the wind optimal profile (speed and generated power), algorithms with dynamic simulations of the operation at low and high speed were developed [40]. The results obtained show that for the situation of minimum torque ripple, the magnetic and electric losses are high and the efficiency is decreased. Moreover, for situations of minimum losses, the torque ripple, which is associated with mechanical stress, is higher. Hence, algorithms that obtain the optimal parameters of the driver were proposed to improve the performance of SRG in wind energy systems. The simulation results are processed to obtain the minimization of the cost function (6). The variables used in the cost function are torque ripple $T_{\text {rip }}$, average phase current $I_{\text {med }}$, and the maximum flux linkage $\Phi_{\max }$. Equations with the optimal firing angles of the SRG for low and high operation speeds were obtained using the proposed algorithms

$$
\left.f_{c}\left(\theta_{\text {on }}\right)\right|^{\theta_{\text {off }}}=\bar{T}_{\text {rip }}\left(\theta_{\text {on }}\right)+\bar{I}_{\text {med }}\left(\theta_{\text {on }}\right)+\bar{\Phi}_{\text {max }}\left(\theta_{\text {on }}\right) .
$$

As a result of the optimization algorithms for operation at low speed, the optimal firing angles can be obtained by

$$
\begin{aligned}
& \theta_{\text {on-opt }}(w)[\mathrm{deg}]=-0.1177 w+51.03 \\
& \theta_{\text {off }-\mathrm{opt}}(w)[\mathrm{deg}]=18
\end{aligned}
$$

For operation at high speeds in single pulse mode, the firing angle $\theta_{\text {on }}$ should be adjusted according to

$$
\begin{aligned}
& w<165 \mathrm{rad} / \mathrm{s} \Rightarrow \theta_{\text {on-opt }}(w)=-0.098 w+55 \\
& w \geq 165 \mathrm{rad} / \mathrm{s} \Rightarrow \theta_{\text {on-opt }}(w)=39 .
\end{aligned}
$$

\section{Direct POWER CONTROLS}

The SRG control system should regulate the power generated at the maximum aerodynamic efficiency point to capture the wind power more efficiently, that is, $P_{\mathrm{ref}}=P_{\mathrm{opt}}=k_{\mathrm{opt}} w_{r}^{3}$, where $P_{\text {ref }}$ is the power required in the SRG output. Two modes of activation and DPC for the SRG are proposed according to the operating speed. In the following, these controls are described.

\section{A. Direct Power Control Operation at Low Speeds (DPC-LS)}

For speeds where the EMF is lower than the dc bus voltage, the power control system is based on the adjustment of the reference current $I_{\text {ref }}$ of activation through hysteresis. The average power generated $P_{\text {med }}$ (see Fig. 1) is obtained from the average value of the product between the voltage $V_{\mathrm{DC}}$ and the electric current $I_{e}$ of the dc link, which has its value obtained using a Butterworth low-pass filter of second order with cutoff frequency $w_{c}=10 \mathrm{~Hz}$ [see (3)]

$$
P_{\mathrm{med}}(s)=V_{\mathrm{DC}} \cdot I_{e} \frac{w_{c}^{2}}{s^{2}+\sqrt{2} w_{c} s+w_{c}^{2}} .
$$

The "pulse generator" stage (see Fig. 1) is responsible for activating SRG stages and performing hysteresis control. The optimal firing angles $\theta_{\text {on }}$ and $\theta_{\text {off }}$ are adjusted in accordance with the SRG operation speed by (7).

\section{B. Direct Power Control Operation at High Speeds (DPC-HS)}

At high speeds, DPC is performed by varying the firing angle $\theta_{\text {off }}$ to allow a single pulse operation. This control is based on the principle that the longer the SRG excitation stage, the greater is the generated power. In this paper, unlike the studies [1], [28], [31], [32], the firing angles are not set randomly. For high speed, the optimal firing angle $\theta_{\text {on }}$ is adjusted in accordance with the SRG operation speed given by (8).

\section{DPC by PI Controller}

The DPCs, DPC-LS, and DPC-HS were initially tested using a PI controller. The controls developed were named DPC-LS-PI and DPC-HS-PI.

1) DPC-LS-PI: It consists in processing the error of generated power $\left(e_{P}=P_{\text {ref }}-P_{\text {med }}\right)$ by a PI controller. The current hysteresis reference $I_{\mathrm{ref}}$ is then obtained as

$$
I_{\text {ref }}=K_{\mathrm{pbv}} e_{P}+K_{\mathrm{ibv}} \int e_{P} d t
$$

where $K_{\mathrm{pbv}}$ is the proportional gain and $K_{\mathrm{ibv}}$ is the integral gain of the PI controller.

2) DPC-HS-PI: The angle $\theta_{\text {off }}$ is obtained through processing of $\left(e_{P}\right)$ by a PI controller as

$$
\theta_{\text {off }}=K_{\text {pav }} e_{P}+K_{\text {iav }} \int e_{P} d t
$$

where $K_{\text {pav }}$ is the proportional gain and $K_{\text {iav }}$ is the integral gain of the PI controller.

Initially, the model of the plant was obtained using Simulink's system identification toolbox. Then, the PI controller gains were 


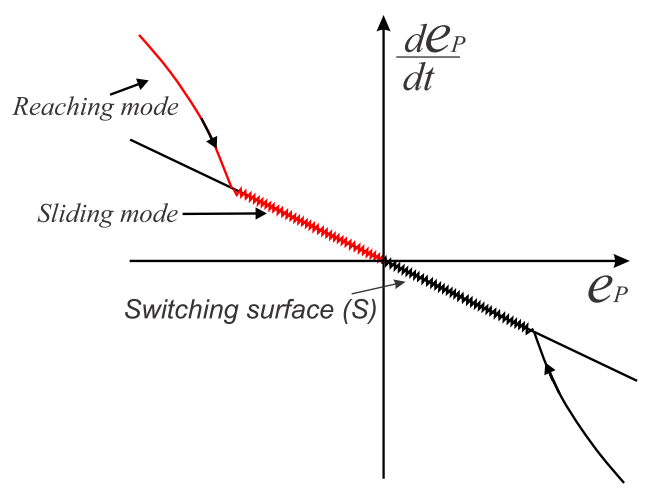

Fig. 6. Operating principle of the SM control.

adjusted using Ziegler-Nichols' second tuning method, as described in [41]. These parameters were set to obtain an answer without overshoot during transient $(\zeta=1)$.

\section{DPC Using Sliding Modes Controller (DPC-SM)}

The average generated power is obtained using a low-pass filter. This may slow down the response of the control system. Therefore, controllers that have a control effort greater than that of PI controllers must be used to obtain a shorter time response without overshoot. To improve the performance of the power controllers, SM controllers in the DPC's are proposed. The developed controls were named DPC-LS-SM and DPCHS-SM.

1) DPC-LS-SM: In DPC-LS-SM, the processing of $e_{P}$ is performed by nonlinear SM controllers. The operating principle of the SM control used can be reviewed in detail in [42] and [43]. The main idea of the control method is to drive the state of the system's initial condition to the desired state by a switching surface $S$. The desired state is the point origin of the phase plane. By using an appropriate design and alternating the system structure constantly, the response of a system can be stabilized [44].

The objective of the SM control method is to make the system status go to the point at which the power error and the derivative of the power error are equal to zero, and remain at that point. If the system status is such that $S \neq 0$, a control effort is made to take it to a new condition near the switching surface. The system dynamics are now controlled by the dynamics imposed by $S=0$ because the system status is prevented from leaving the surface by the controller, rapidly producing a large control effort to keep the system very close to the switching surface. In DPC, the objective is to control the active power generated by the SRG. Therefore, the switching surface is defined according to the error between the power reference and the current value of the generated power (see Fig. 6). Based on [44], the switching surface $S$ is defined as

$$
S=e_{P}+k d \frac{d e_{P}}{d t}
$$

where $k d$ is a constant set according to the desired system response.

Thereafter, the controller was designed based on the principle that the SRG power can be controlled using the performance in

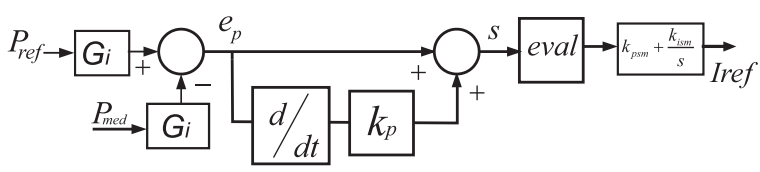

Fig. 7. SM controller used in the DPC-LS-SM.

the reference current $I_{\text {ref }}$. The control rule that reproduces this behavior is given by

$$
I_{\text {ref }}=\left(k_{\mathrm{psm}}+\frac{k_{\text {ism }}}{s}\right) \operatorname{eval}(S)
$$

where $k_{p}$ and $k_{i}$ are the controller gains and the function eval is responsible for determining the reaction of the system according to the status position in the status space.

Function eval was used as a linear gain with saturation, as

$$
\operatorname{eval}\left(s_{1}\right)= \begin{cases}s_{1} k_{e}, & \text { if } l_{\min }<s_{1} k_{e}<l_{\max } \\ l_{\max }, & \text { if } s_{1} k_{e}>l_{\max } \\ l_{\min }, & \text { if } s_{1} k_{e}<l_{\min }\end{cases}
$$

where $k_{e}$ is the function gain eval and $l_{\min }$ and $l_{\max }$ are the minimum and maximum limits, respectively.

Implementation of the system with power control in SMs for SRG is represented in the form of a block diagram in Fig. 7. The power reference signal is compared with the value of the measured power and the surface $S$ is calculated using (12).brk The control rule shown in (13) is applied to the surface $S$ and the value $I_{\text {ref }}$ is regulated to obtain the desired generated power.

2) DPC-HS-SM: An SM controller was also used in the DPC-HS-SM. In this case, the control rule that reproduces this behavior is given by

$$
\theta_{\text {off }}=\left(k_{\mathrm{psmh}}+\frac{k_{\mathrm{ismh}}}{s}\right) \operatorname{eval}(S)
$$

Sliding mode parameters design and analysis of stability were performed by proceedings described in [42] and [45]. These parameters were set to get an answer without overshoot during transient. The sliding surface is designed to enforce SM operation with first-order dynamics. In the SM, the control laws (13) and (15) restrict the system state onto the surface, and its behavior is exclusively governed by $S=0$ [42], [45]. Therefore, the first-order linear error dynamics of the generated power result from (12) as

$$
k d \frac{d e_{P}}{d t}=e_{P}
$$

Thus, the constants are selected so as to impose the desired dynamics on the control errors (16). The control variables (13) and (15) have two components: a discontinuous one controlled by $k_{\mathrm{psmh}} \operatorname{eval}(S)$, and a linear slow motion controlled by $k_{\text {ismh }} / s$ eval $(S)$. Although a large $k_{\text {psmh }}$ value accelerates the power response during transients, on the other hand, it increases the chattering in the steady state. A large $k_{\text {ismh }}$ value makes the quasi-linear behavior dominates. An adequate gain selection must ensure balance between quasi-linear behavior, PI specific behavior, and switching. Making this selection properly, the power error can be significantly reduced, while the transient operation and the robustness are not much compromised [42]. 


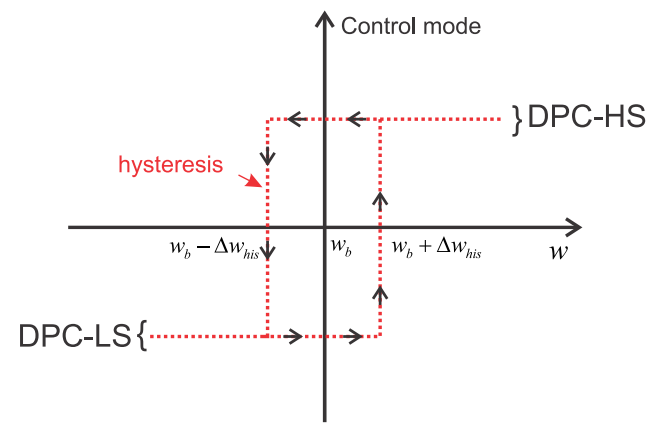

Fig. 8. Commutative system.

The robustness with respect to parameter deviations and perturbations is an important aspect. The SM design procedure [42], [45] requires the variable structure controller gains be large enough to compensate model uncertainties, perturbations, and to assure the stability. Large enough values for the proportional gains $k_{\mathrm{psmh}}$ and $k_{\text {ismh }}$ satisfy the stability condition $(S . d S / d t<0)$ [44].

\section{Commutative System}

For operation throughout a wide speed range, the DPC-LS and DPC-HS controls should be joined. Thus, a commutative system is proposed. The switch operation is based on a hysteresis system (see Fig. 8) that reduces the frequency of switching between the control modes if the speed is varying near the base speed $w_{b}$. In addition, the hysteresis $\Delta w_{b}$ substantially reduces the switching in the system because of signal acquisition noise.

Fig. 1 shows the complete power control system of the SRG with the control switch. The output of the control switch performs the switching of the activation variables. For low speeds, the pulse generator receives the current $I_{\text {ref }}$ from the DPC-LS controller, whereas the activating angles $\theta_{\text {on }}$ and $\theta_{\text {off }}$ are obtained from the optimization equations for low speeds, see (7). At high speeds, $\theta_{\text {off }}$ is obtained from the DPC-HS controller and the current reference $I_{\text {ref }}$ is set with the maximum value allowed to protect the SRG phases. The firing angle $\theta_{\text {on }}$ is obtained from the optimization equations for high speeds, see (8).

To ensure the system's stability during the switching of control modes, the memory variables and output of the controllers must be reset. However, this may decrease the power generated during switching. Thus, the use of an initial feedback in the output variable was proposed at the time when the systems are switched. When switching from DPC-HS to DPC-LS, the current in the SRG phase, at the time when the last activated phase turns off, is determined and is taken as the initial value of the control DPC-LS output. When switching from DPC-LS to DPC-HS, the initial angle $\theta_{\text {off }}$ of the output corresponding to half the angle $\theta_{\text {off }}$ used in the DPC-LS control is added.

\section{VSC CONTROL}

The VSC, shown in Fig. 1, controls the voltage $V_{\mathrm{DC}}$ and it allows to generate power flow from the SRG to the grid, controlling the power factor. The VSC controls are realized in the synchronous coordinate system $(d q)$ employing the grid voltage angle $(\theta=w t)$ used in the transformation $a b c-d q$, which is obtained using a phase-locked loop (PLL). The control strategy applied to the VSC consists basically of two control loops (see Fig. 1). The currents $i_{d}$ and $i_{q}$ are controlled by two PI controllers $K_{d}(s)$ and $K_{q}(s)$, which process the error between the currents $i_{d \text { ref }}-i_{d}$ and $i_{q \text { ref }}-i_{q}$. The voltage $V_{\mathrm{DC}}$ is regulated by the controller $K(s)$, which is connected to the control loop of current $i_{d}$. The control loop of current $i_{q}$ is responsible for controlling the power factor of the power sent to the electrical grid, and thus, a good dynamic response is an important property for this current control.

Through the modeling performed in detail in [46], the transfer function of voltage loop $G_{v}(s)$ is obtained

$$
\begin{aligned}
G_{v}(s) & =\frac{\delta V_{\mathrm{DC}}^{2}(s)}{P(s)}=-\left(\frac{2}{C}\right) \frac{\tau s+1}{s} \\
\tau & =\frac{2}{3} \frac{L P_{\mathrm{ext}}}{\widehat{V}^{2}} .
\end{aligned}
$$

\section{DESIGN OF THE VSC}

The design of a VSC is divided in two stages: the ac and the dc designs. In the ac design, the objective is to find the value of the coupling inductors $L$, whereas in the dc design stage, the focus is the calculation of the link capacitor $C$.

\section{A. Calculation of Inductor $L$}

The design of the coupling inductor is based on the analysis of the current ripple in the line for finding $L$. The project of the inductance depends on whether PWM is used or not. In this paper, the design in case of using the PWM center aligned or left aligned is given. In these cases, it is possible to use (19), whose dimension can be obtained in [47]-[49]. The value of the inductance $L$ is computed through the value of the dc bus voltage $V_{\mathrm{DC}}$, VSC switching frequency $f_{\mathrm{sw}}$, and of the desired current ripple $I_{\text {ripple. }}$ If current ripple decreases, the quality of the energy sent to the electrical grid through the VSC tends to increase

$$
L=\frac{V_{\mathrm{DC}}}{6 . I_{\text {ripple }} \cdot f_{\mathrm{sw}}} .
$$

In this paper, $L=10 \mathrm{mH}$ inductors were used, since they were available at the laboratory. Hence, as $f_{\mathrm{sw}}=10 \mathrm{kHz}$ and $V_{\mathrm{DC}}=400 \mathrm{~V}$, the calculated current ripple is $I_{\text {ripple }}=$ $0.6667 \mathrm{~A}$.

\section{B. DC-Link Capacitor Calculation}

The project of the dc bus capacitor is a crucial stage in the VSC design, since higher values of voltage ripple may lead to a decay in the VSC behavior and, also, may cause torque oscillations in the SRG. There are some methodologies to compute the capacitor value in VSC systems, as found in [47] and [50]. However, for systems employing SRG, a different analysis has to be done because, in this case, the power source current $I_{e}$ flows in both directions of operations. On the SRG excitation stage, the current flows from the capacitor to the SRG, and on 


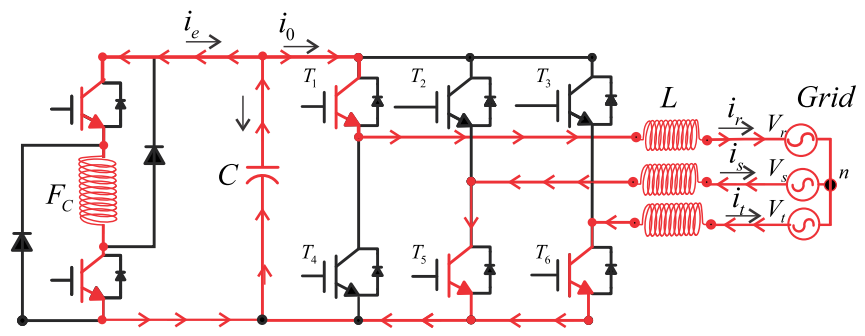

(a)

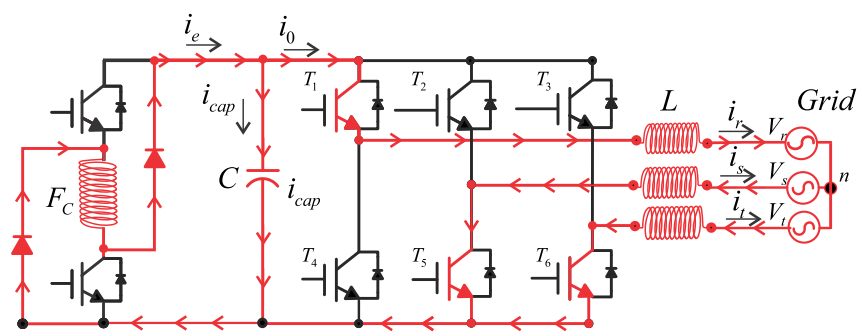

(b)

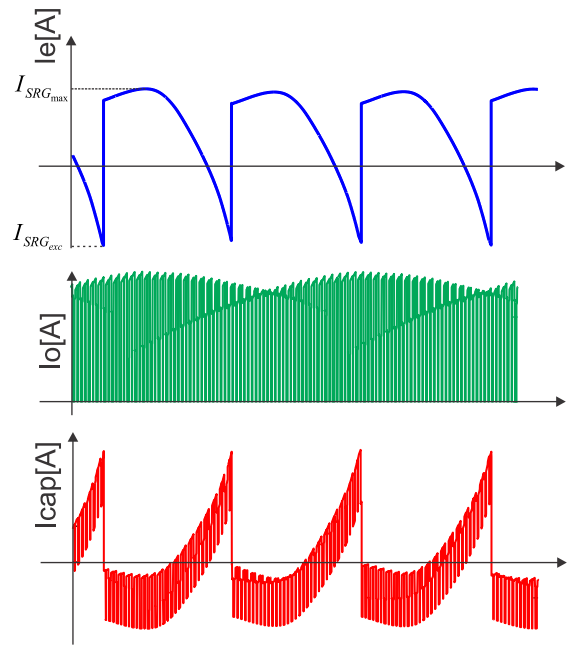

(c)

Fig. 9. Design of the VSC's components. (a) Excitation stage. (b) Generation stage. (c) Currents of the dc link.

the generation step, it flows in the inverse direction. Hereafter, the methodology used to determinate the capacitor value is explained.

In one control cycle, the variation of voltage in the capacitor is represented through the following equation:

$$
v_{\text {cap }}\left(t_{f}\right)-v_{\text {cap }}\left(t_{i}\right)=\frac{1}{C} \int_{t_{i}}^{t_{f}} i_{\text {cap }}(t) . d t
$$

where $t_{f}=t_{i}+t_{\mathrm{ch}}=t_{i}+\frac{1}{f_{s} w}$, and $t_{f}$ and $t_{i}$ are the final and initial times, respectively.

The capacitor current, shown in Fig. 9(a), is calculated by $i_{\text {cap }}=i_{o}-i_{e}$. As $i_{o}=S_{r} i_{r}+S_{s} i_{s}+S_{t} i_{t}$ where $S_{r}, S_{s}, S_{t}$ are the switching stage, then

$$
i_{\text {cap }}=S_{r} i_{r}+S_{s} i_{s}+S_{t} i_{t}-i_{e} .
$$

As described in [47], the switching state 001 can be selected for the analysis, as the resulting analysis of the other switching
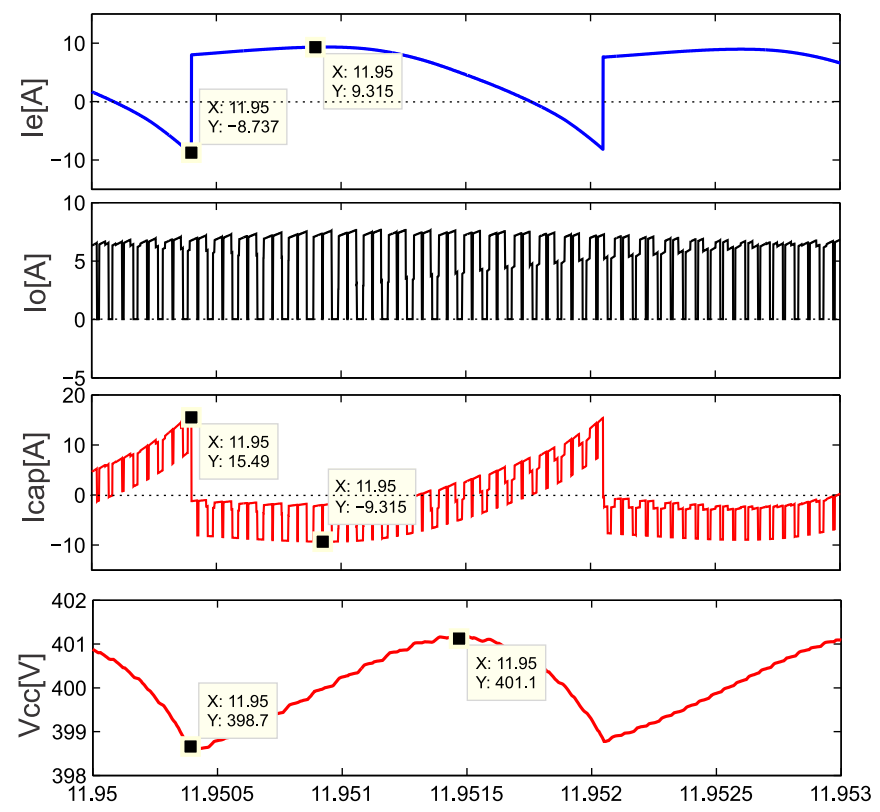

Fig. 10. Simulation results of voltage ripple estimation.

states will result in the same conclusion. In this case, $i_{\text {cap }}=$ $i_{e}-i_{r}$.

The voltage ripple in the capacitor is defined as $v_{\text {ripp }}=$ $v_{\text {cap }}\left(t_{f}\right)-v_{\text {cap }}\left(t_{i}\right)$ and it is supposed that the power factor is corrected by the controller $(\mathrm{PF}=1)$, then

$$
v_{\text {ripple }}=\frac{1}{C}\left(I_{r} \sin (w t)-i_{e}\right) \cdot\left(t_{f}-t_{i}\right) .
$$

As the switching frequency is very high compared with $60 \mathrm{~Hz}$ and with the frequency of the current $I_{e}$, then $i_{\text {cap }}$ is almost constant during $t_{f}-t_{i}=T_{\mathrm{sw}}$. Thus

$$
v_{\text {ripple }}=\frac{1}{C}\left(I_{r} \sin (w t)-i_{e}\right) \cdot T_{\mathrm{sw}} .
$$

The worst case of the sinusoidal wave is at its maximum value $\sin (w t)=1$. The current $i_{e}$ has a negative value at the stage of SRG phase excitation as observed in Fig. 9(a). In this case, the higher value of $i_{e}$ is equal to $I_{\mathrm{SRG}_{\mathrm{exc}}}$. Hence

$$
C=\frac{1}{v_{\text {ripple }}}\left(I_{r}+I_{\mathrm{SRG}_{\mathrm{exc}}}\right) \cdot T_{\mathrm{sw}} .
$$

At the generation stage [see Fig. 9(b)], the current $i_{\text {cap }}$ has a higher value when $\sin (w t)=0$ and $i_{e}$ is equal to $I_{\mathrm{SRG}_{\mathrm{max}}}$. In this case

$$
C=\frac{1}{v_{\text {ripple }}}\left(I_{\mathrm{SRG}_{\mathrm{max}}}\right) \cdot T_{\mathrm{sw}} .
$$

Knowing the values $I_{\mathrm{SRG}_{\mathrm{max}}}, I_{r}, I_{\mathrm{SRG}_{\mathrm{exc}}}$ at the operation point of nominal power is possible to calculate the desired capacitance to obtain the maximum desired ripple. In this case, $I_{\mathrm{SRG}_{\max }}=$ $9.3 \mathrm{~A}, I_{r}=7.4 \mathrm{~A}, I_{\mathrm{SRG}_{\mathrm{exc}}}=8.3 \mathrm{~A}$, and $v_{\text {ripple }}=2 \mathrm{~V}$, which result in capacitors values of $785.37 \mu \mathrm{F}$ and $796.29 \mu \mathrm{F}$. As an industrial VSC SKS22FB6U (Semikron) was available at the lab, with capacitance value of $C=1360 \mu \mathrm{F}$, both conditions were satisfied. Fig. 10 depicts the simulation results employing 


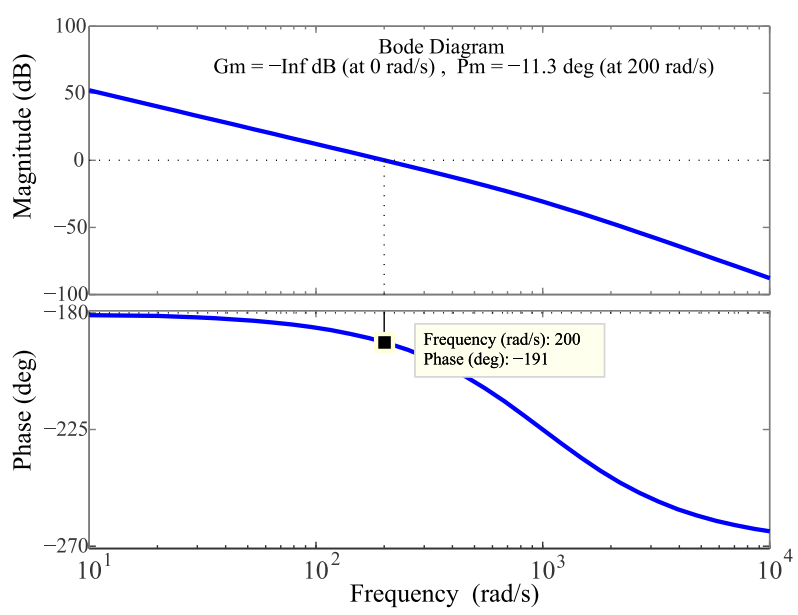

(a)

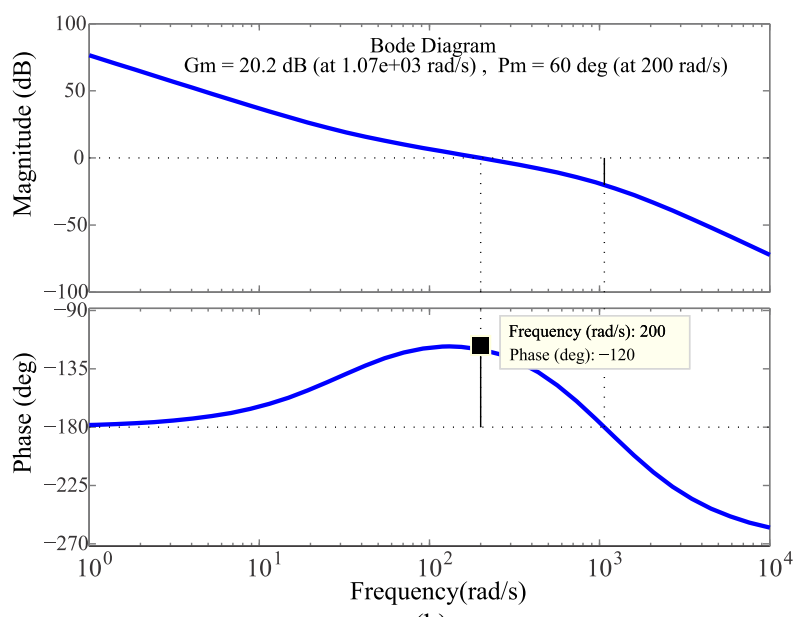

(b)

Fig. 11. Bode diagram of voltage control. (a) Without $K_{v}(s)$. (b) With $K_{v}(s)$.

the capacitor $C=1360 \mu \mathrm{F}$ and a ripple of $1.1 \mathrm{~V}$ and $1.3 \mathrm{~V}$ was observed.

\section{Design of VSC Controllers}

The setting of the current controller is given by

$$
K(s)=\frac{K_{p i} s+K_{i i}}{s}
$$

where $K_{p i}$ and $K_{i i}$ are proportional and integral gains.

The PI controller gains depend on the inductive filter parameters so that $K_{p i}=\frac{L_{l}}{\tau_{i}}$ and $K_{i i}=\frac{R_{l}}{\tau_{i}}$. Inductor parameters are $L_{l}=10 \mathrm{mH}$ and $R_{l}=0.15 \Omega$. Thus, the current controllers could be determine for $\tau_{i}=1 \mathrm{~ms}(w i=1000 \mathrm{rad} / \mathrm{s})$.

For the voltage control, the desired phase margin was set up equal to $60^{\circ}$ and $w_{c v}=0.2 w i=200 \mathrm{rad} / \mathrm{s}$. To ensure a zero steady-state error, the controller $K_{v}(s)$ must have an integrator; moreover, $K_{v}(s)$ is multiplied by $-\left(\frac{C}{2}\right)$. Initial phase margin $\Theta_{M n c}=-11.3$ was determined according to the system frequency response without a compensator [see Fig. 11(a)]. Thus, the compensator lead $N(s)$ was determined to add $\Theta_{M}=71.3$

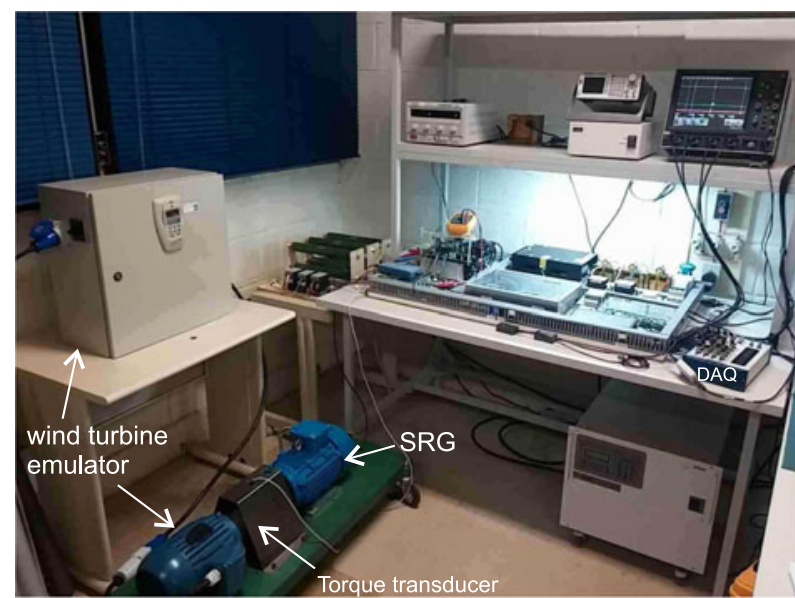

Fig. 12. Experimental setup.

in the system phase margin [see Fig. 11(b)]

$$
\begin{aligned}
K_{v}(s) & =-\left(\frac{C}{2}\right) \frac{N(s)}{s} \\
N(s) & =n_{o} \frac{s+\left(\frac{p}{\alpha}\right)}{s+p} .
\end{aligned}
$$

\section{Performance Tests}

The proposed system was precisely modeled to achieve results consistent with the practical reality. A nonlinear model of an SRG based on experimental magnetization curves was developed. Power electronic converters were performed using blocks of the SimPowerSystem library from Simulink.

For experimental confirmation of the DPCs, an experimental setup (see Fig. 12) was assembled. To simulate a wind turbine, a $2.2 \mathrm{~kW}$ three-phase induction motor (IM) was coupled to the SRG. Through a frequency inverter, the IM operating speed could be controlled. The SRG and IM were connected by a torque transducer model HBMT22/50NM. A central control board was developed, which has a digital signal processor (TMS320F28335), signal conditioning circuits, and protection and isolation circuits. Furthermore, this circuit board also has communication circuits between the DSP and peripherals: an SSI absolute encoder with a 12 bit resolution and a digital analog converter that allows taking the experimental results in the oscilloscope. As AHB converters are not commercially available, a converter was designed for use in the test.

In earlier tests, the DPCs for low and high speeds were tested. The power control systems, DPC-LS and DPC-HS, were modeled and simulated using Simulink/MATLAB software. These tests of controls were implemented on the experimental platform. The results of the systems connected to the grid are presented. An experimental test for variable speed operation was conducted to validate the commutative system of power control. Finally, a simulation emulating the wind turbine system was created to verify the operation of the proposed system for use of the SRG in wind generation. 


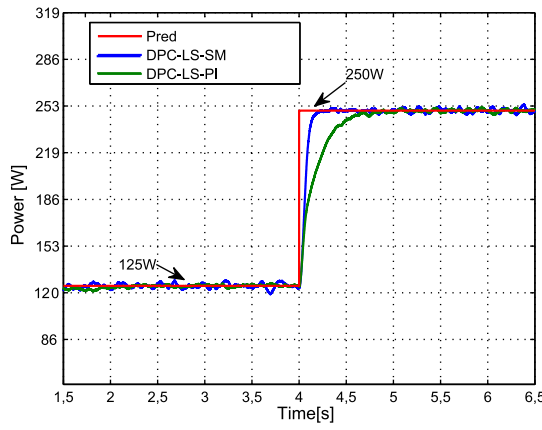

(a)

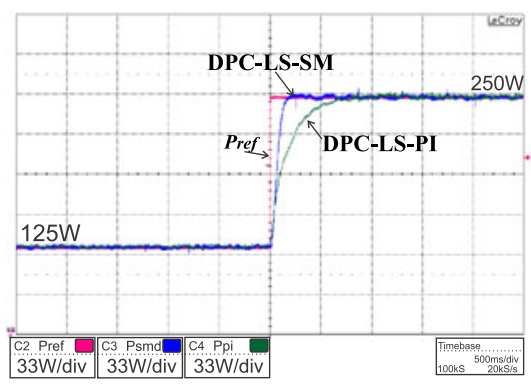

(d)

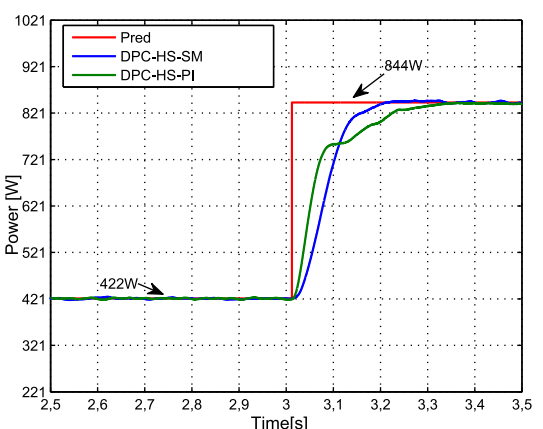

(b)

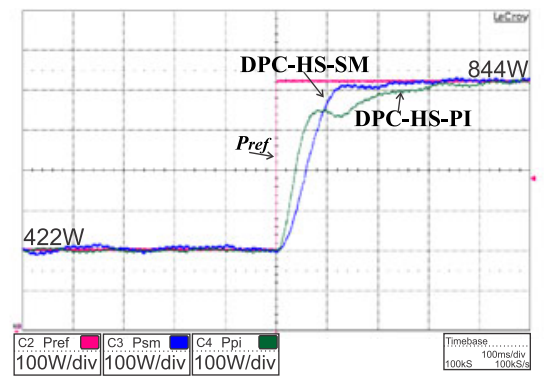

(e)

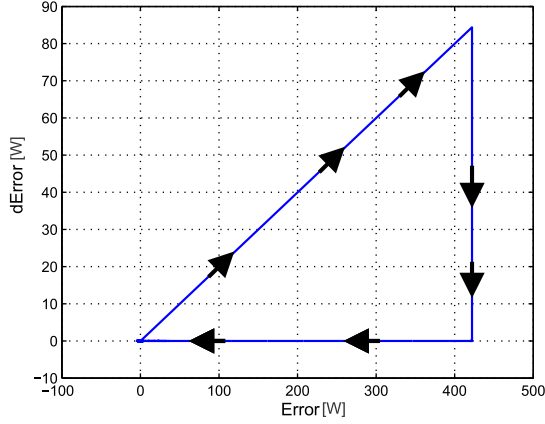

(c)

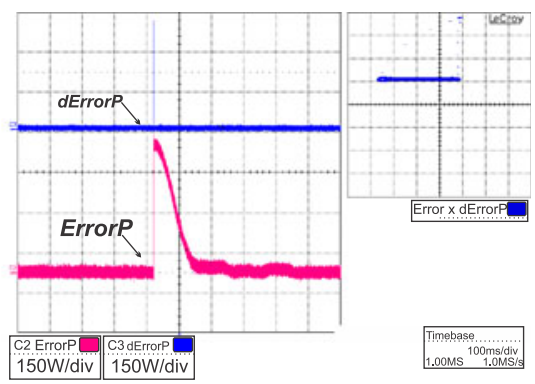

(f)

Fig. 13. Results of DPCs tests. (a), (b), (c) Simulation. (d), (e), (f) Experiment. (a), (d) DPC-LS. (b), (e) DPC-HS. (c), (f) Error $e_{p}$ and $d \frac{d e_{p}}{d t}$.

TABLE I

PERFoRMANCE PARAMETERS OF THE DPC

\begin{tabular}{lccc}
\hline \hline Control & Set. time & Overshoot & Max. erro tracking \\
\hline DPC-LS-PI & $700 \mathrm{~ms}$ & no & $1.6 \%$ \\
DPC-LS-SM & $200 \mathrm{~ms}$ & no & $1.2 \%$ \\
DPC-HS-PI & $350 \mathrm{~ms}$ & no & $0.94 \%$ \\
DPC-HS-SM & $200 \mathrm{~ms}$ & no & $0.35 \%$ \\
\hline \hline
\end{tabular}

\section{A. DPC Tests}

1) Direct Power Control at Low Speeds: A power reference to be generated by the SRG with speed equal to $80 \mathrm{rad} / \mathrm{s}$ (746 r/min) was created. Fig. 13(a) and (d) shows that the results for the simulation and the experiment for the DPC-LS-PI and DPC-LS-SM are highly similar. This verifies the accuracy of the modeling performed in the simulations. Table I shows obtained performance of the DPC. It was observed that the power reference was achieved by the proposed power control systems. However, as expected, better performance results in both the simulation and the experiment were achieved by applying the DPC that uses the SM controller than by applying the DPC that uses only the PI controller. The high control effort characteristic of the SM controller allowed a settling time of $200 \mathrm{~ms}$ to be obtained, whereas the PI controllers produced a settling time of $700 \mathrm{~ms}$. Small maximum power error tracking was obtained. But, again, the DPC-LS-SM presented better result (1.2\%). Table I shows the obtained performance parameters of the DPC.

2) Direct Power Control at High Speeds: A power reference to be generated by the SRG with speed equal to $120 \mathrm{rad} / \mathrm{s}$ $(1146 \mathrm{r} / \mathrm{min})$ was created. It was observed that the power reference was achieved by the proposed power control systems, as shown in Fig. 13(b) and (e). The DPC-HS-SM had a settling time of $200 \mathrm{~ms}$, whereas the PI controllers gave a settling time of $350 \mathrm{~ms}$. Fig. 13(c) shows the phase plane of the control system DPC-HS-SM for the simulation. The arrows indicate the route of the status $\left(e_{P}, \frac{d e_{P}}{d t}\right)$. It was observed that after the reference power degrees, the system was driven to the switching surface (reaching mode). After reaching the switching surface, the system status was driven to the plane origin (SM), where it was captured. Fig. 13(f) shows the imprisonment of the system state in the plane origin during the experiment, proving the functionality of the SM controller used.

\section{B. Generation Connected to the Electrical Grid}

Results from the tests for the power controls for the SRG connected to the electrical grid are presented below.

1) Operation at High Speeds: For the SRG operating at $135 \mathrm{rad} / \mathrm{s}(1290 \mathrm{r} / \mathrm{min})$, a step was applied in the reference of power generated. In this case, the generated power increased from 800 to $1200 \mathrm{~W}$, which is the optimal power generation at $135 \mathrm{rad} / \mathrm{s}$. Fig. 14(a) shows the increase in the SRG current $I_{A}$ and the action of the VSC control to increase the electrical current sent to the electrical grid.

Fig. 14(b) and (c) shows the SRG variables operating at $135 \mathrm{rad} / \mathrm{s}$ and generating $1200 \mathrm{~W}$, which are sent to the electrical grid by the VSC. The SRG phases were activated by a single pulse, as can be seen in Fig. 14(b). The electric currents in the SRG phases increased after the excitation stage, at the moment when the switches F1 and F1B were turned OFF, which indicates a reduction in the excitation factor, implying a higher SRG efficiency. The experimental results [see Fig. 14(b)] show that the voltage in SRG phase A is under the magnetic influence 


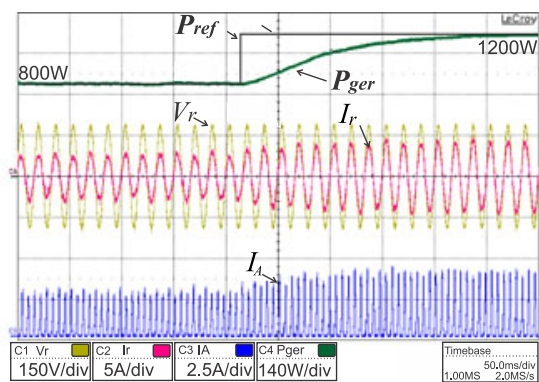

(a)

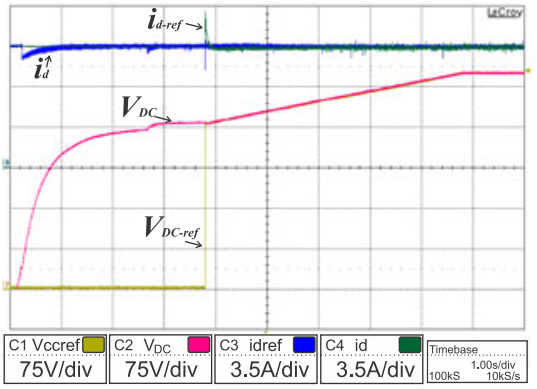

(d)

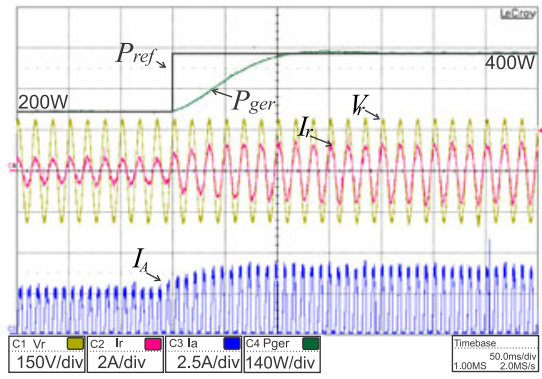

(g)

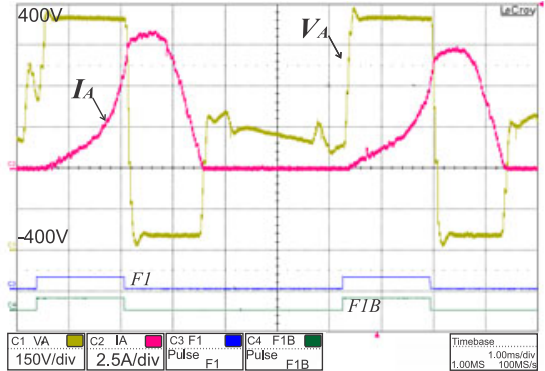

(b)

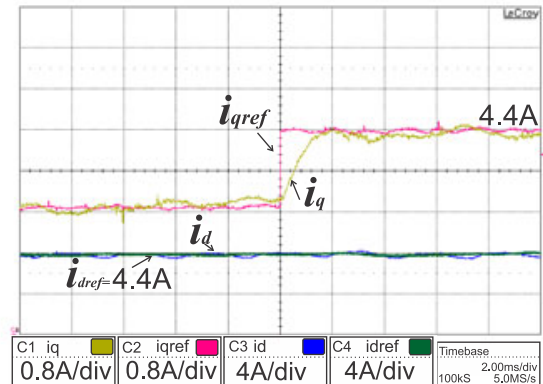

(e)

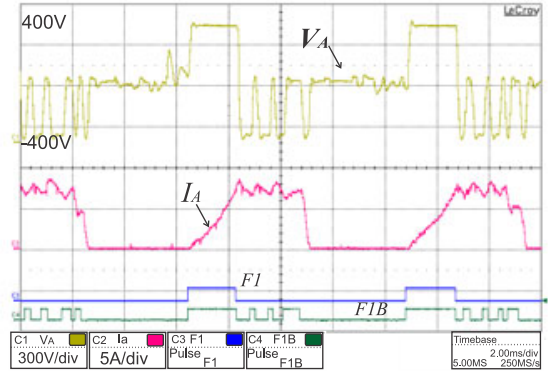

(h)

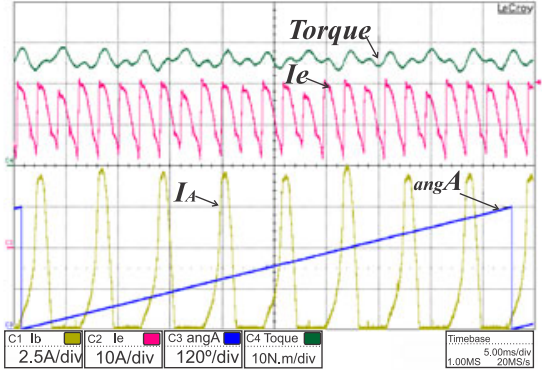

(c)

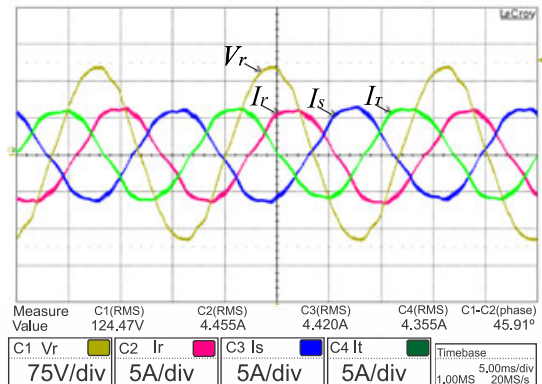

(f)

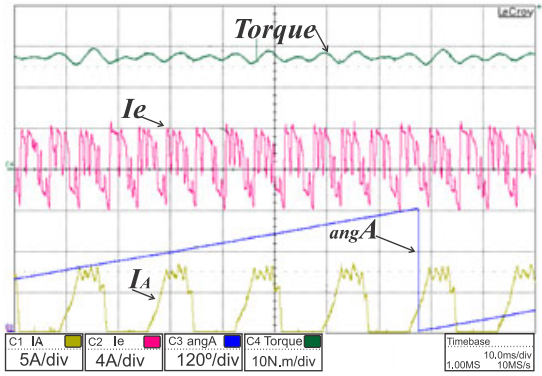

(i)

Fig. 14. Experimental results at generation connected to the electrical grid. (a) Generated power, current, and voltage in phase A of SRG, and current $I_{R}$ of the electrical grid at $135 \mathrm{rad} / \mathrm{s}$. (b) Voltage and electric current in phase A of SRG at $135 \mathrm{rad} / \mathrm{s}$. (c) Electromechanical torque, electric current $I_{e}$, and angle $\theta_{A}$ at $135 \mathrm{rad} / \mathrm{s}$. (d) DC-link voltage initialization. (e) Step in $i q$. (f) Three-phase currents $(\mathrm{P}=1200 \mathrm{~W}$ and $\mathrm{Q}=1200 \mathrm{VAr}$ ). (g) Generated power, current, and voltage in phase A of SRG, and current $I_{R}$ of the electrical grid at $95 \mathrm{rad} / \mathrm{s}$. (h) Voltage and electric current in phase A of SRG at $95 \mathrm{rad} / \mathrm{s}$. (i) Electromechanical torque, electric current $I_{e}$, and angle $\theta_{A}$ at $95 \mathrm{rad} / \mathrm{s}$.

of the other phases at the moments of switching when voltages were induced; however, as the F1 and F1B switch were turned OFF, there was no electric current in phase A of the SRG.

Fig. 14(c) shows the torque and the electric current in the dc link. In a single pulse operation, the torque ripples are greater than in hysteresis. The electric current $I_{e}$ ranges from negative values in the magnetization to positive values in the generation stage. The average value of this current defines the energy generated by the SRG.

First, the VSC control system performs the synchronization with the electrical grid. Then, the voltage $V_{\mathrm{DC}}$ control [see Fig. 14(d)] is initialized in ramp through the precharge circuit connected to the grid. When $V_{\mathrm{DC}}$ accomplishes the steady state $(400 \mathrm{~V})$, the SRG controller starts operating.

To check the dynamic response of the current control of the converter connected to the electrical grid, a test was conducted in which a step was applied to the reactive power reference. For the SRG generating $1200 \mathrm{~W}$, the reactive power reference increased from 800 to 1200 VAr. Fig. 14(e) shows that the

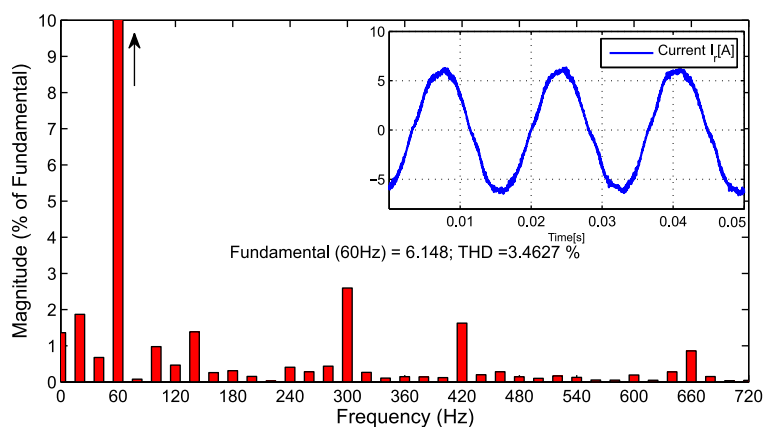

Fig. 15. FFT analysis for the current waveform.

response time, as intended, is equal to $1 \mathrm{~ms}$ and the three-phase currents are sent to the electrical grid. Fig. 14(f) shows the threephase currents when $P=1200 \mathrm{~W}$ and $Q=1200$ VAr. Fig. 15 shows the FFT analysis of the current waveform. Total harmonic distortion (THD) was equal to $3.4 \%$, which is below the value recommended by IEC standards 1000-3-2. This fact confirms 
the feasibility of using the proposed structure to send energy generated by SRG to the electrical grid.

2) Operation at Low Speeds: For the SRG operating at $95 \mathrm{rad} / \mathrm{s}(900 \mathrm{r} / \mathrm{min})$, a step was applied to the active power reference generated by the SRG. In this case, the generated power increased from 200 to $400 \mathrm{~W}$ (which is the optimal power generation at $95 \mathrm{rad} / \mathrm{s})$. Fig. 14(g) shows the increase in the current in phase A and the action of the VSC control to increase the electrical current sent to the electrical grid.

Fig. 14(h) and (i) shows SRG variables when operating at $95 \mathrm{rad} / \mathrm{s}$ generating $400 \mathrm{~W}$. The SRG phases were activated by hysteresis, as shown in Fig. 14(h). The hysteresis was held in the soft-switching mode, with only one switch turned OFF after SRG magnetization. Only the switch F1B is used in the hysteresis control. Low frequency of switch is observed in F1B when compared with systems that use PWM in control of the current. Besides, the voltages on the insulated-gate bipolar transistors during the generation period varied only between $0 \mathrm{~V}$ and $-V_{\mathrm{DC}}$. These factors led to a reduction in the switching losses.

Fig. 14(i) shows the torque and the electric current in the dc link. In the operation by current hysteresis, the torque ripple is smaller than that in the single pulse mode.

\section{Switching System of Power Controls}

To validate the commutative system of power control, a variable speed test was conducted. The speed begins in $900 \mathrm{r} / \mathrm{min}$ and increases by ramp until $1100 \mathrm{r} / \mathrm{min}$. Afterward, the speed returns to $900 \mathrm{r} / \mathrm{min}$. This speed profile was determined for the occurrence of variations between the control modes. The control must pass from DPC-LS-SM to DPC-HS-SM and then return to DPC-LS-SM. The hysteresis of switch was defined equal to $5 \mathrm{rad} / \mathrm{s}$. The reference power for the controls was calculated as a function of the operating speed by (2).

Initially, the commutation system was tested without the use of initial feedback during systems switching. Fig. 16(a) shows the results of this test. It was noted that during the system commutation, transients occurred in the generated power. This happened because the controls started with the reset variables. These abrupt variations in power generated during system switching can cause mechanical damage to the system.

The results shown in Fig. 16(b) were obtained adding initial feedback during the transition. There was a smooth transition between the control modes, avoiding mechanical damage to the generator. The power generated followed the power reference even during speed variations.

The phase current (see Fig. 17) of the SRG during the transitions between control modes indicated a change in the power control mode. The SRG current is slowly falling after (Zoom 1 of Fig. 17) switches were turned OFF (generation step). This occurs because the back emf is increasing when the speed is also increasing, then the switching of the drive modes is necessary because if the back emf becomes higher than the bus voltage, the drive by hysteresis may not be performed, and the power control system does not work properly. At this moment, single pulse control must be activated.

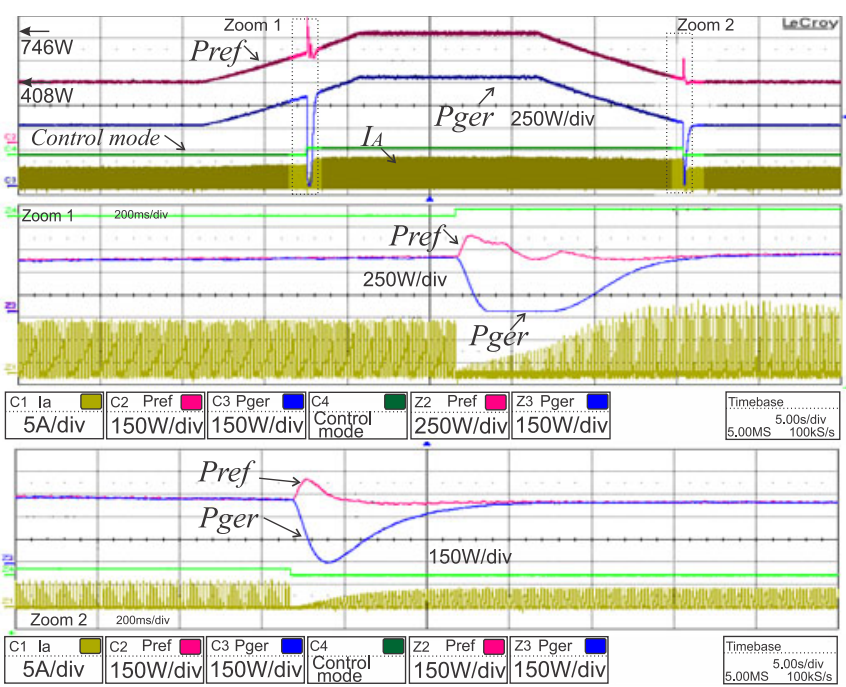

(a)

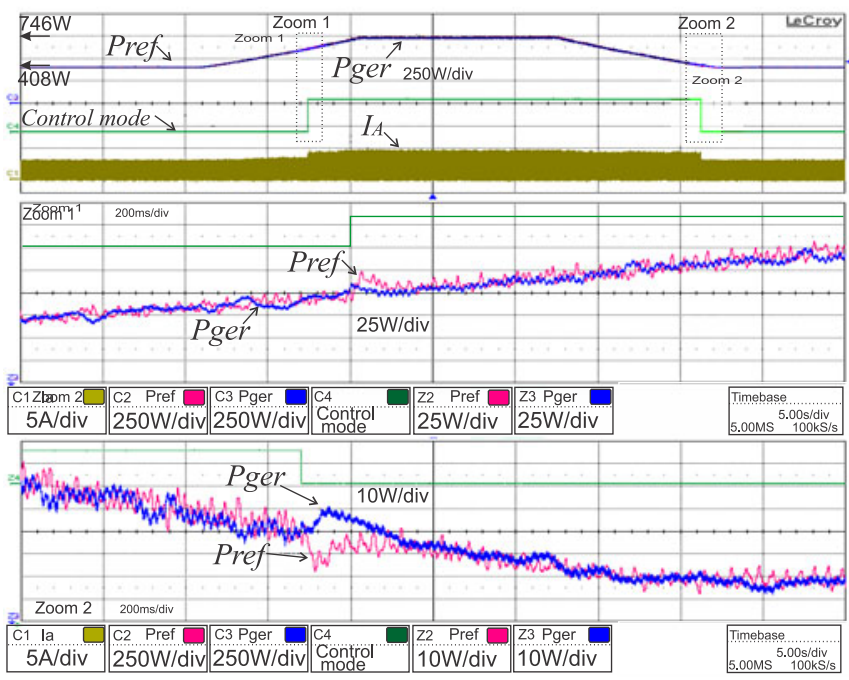

(b)

Fig. 16. Experimental results of commutation controls. (a) Without initial feedback. (b) With initial feedback.

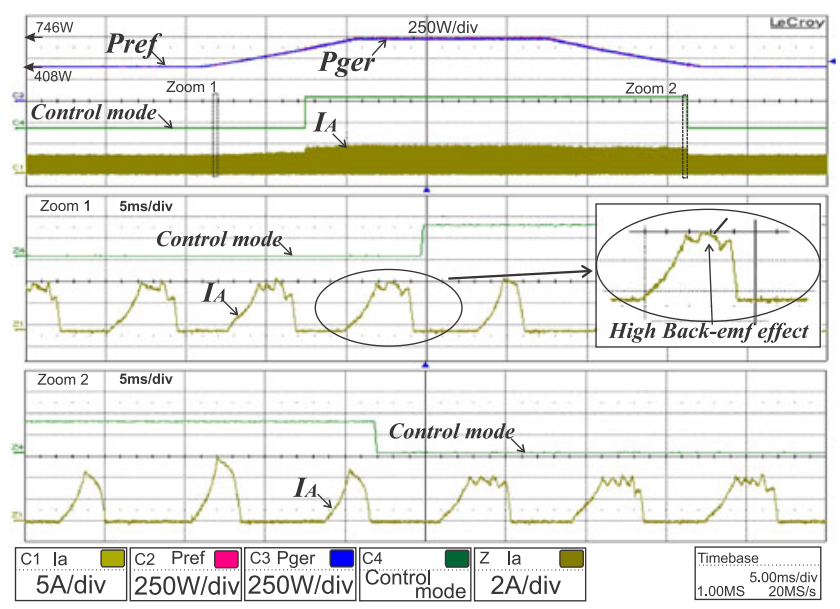

Fig. 17. SRG current $I_{A}$ during switching of controls. 


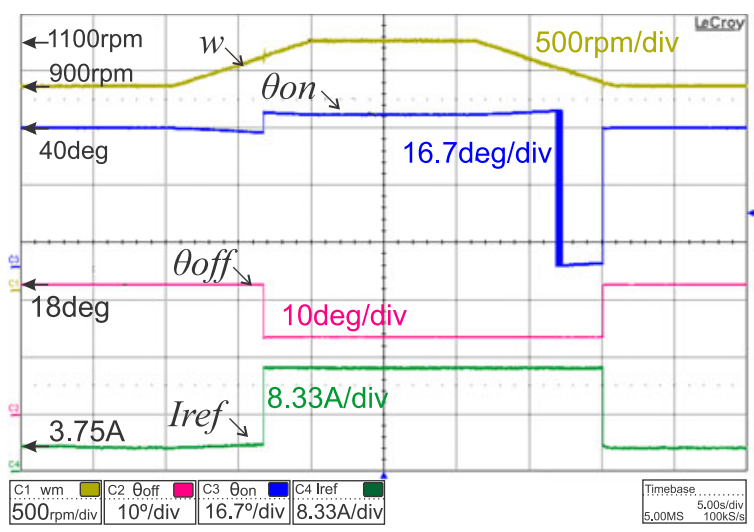

Fig. 18. Speed, firing angles, and $I_{\text {ref }}$ during speed test.

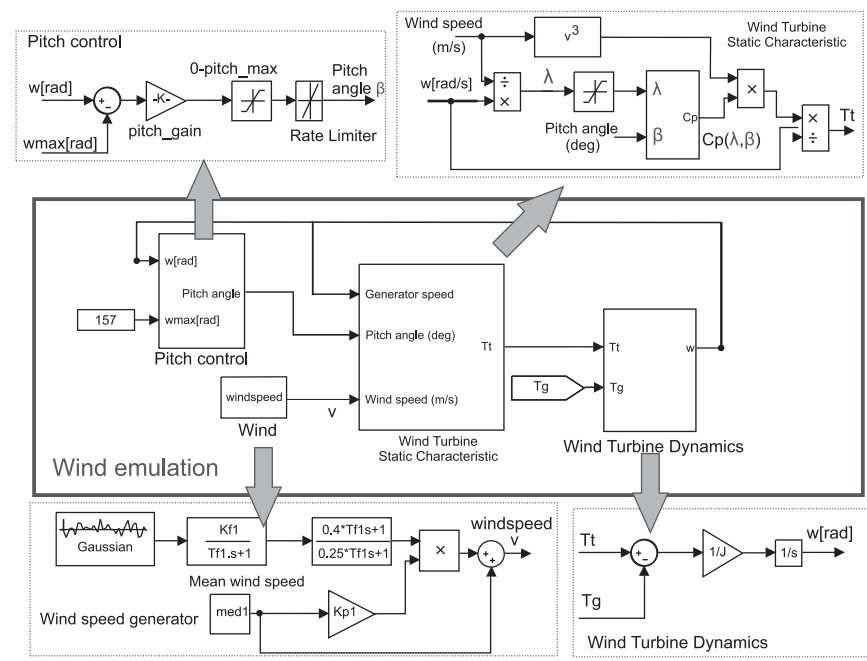

Fig. 19. Wind turbine emulation.

Before the transition from DPC-HS-SM to DPC-LS-SM (Zoom 2 of Fig. 17), even with optimal activation variable adjustments, it was observed that the current in the SRG phase decreased after the excitation period. This was because of a decrease in the back EMF. As this mode of operation should be avoided, activating by hysteresis starts with the control mode change. Fig. 18 shows the drive variables during the experiment. The firing angles were adjusted according to the control mode and operating speed to obtain the optimal conditions, which are defined such that the balance between torque ripples, iron losses, and electric losses are maintained.

\section{Variable Wind Speed Turbine Emulation}

A simulation was conducted emulating a wind turbine system (see Fig. 19) to verify the operation of the proposed system for use of the SRG in wind generation. To obtain a time series of wind speed, the methodology developed in [51] and [52] was used. A Von Karman filter (29) is used to generate the wind time series. The filter is excited by a normalized Gaussian noise and added with the average wind speed

$$
F_{\text {karman }}(s)=K_{f} \frac{0.4 T_{f} s+1}{\left(T_{f} s+1\right)\left(0.25 T_{f} s+1\right)}
$$

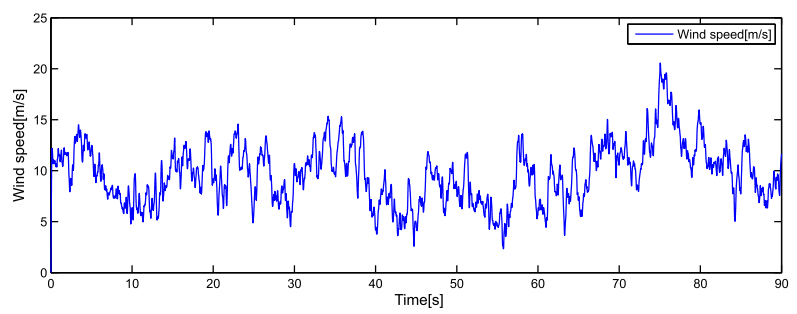

(a)

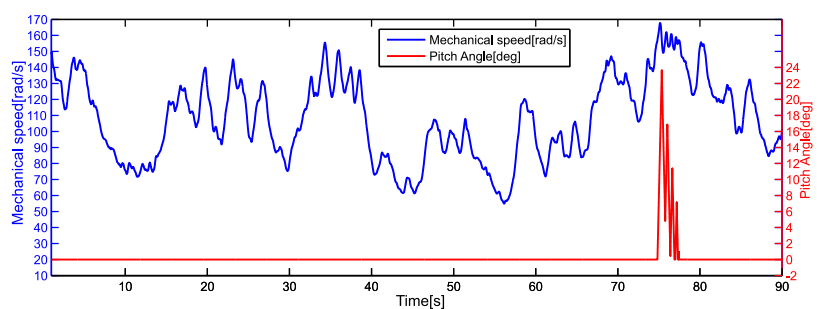

(b)

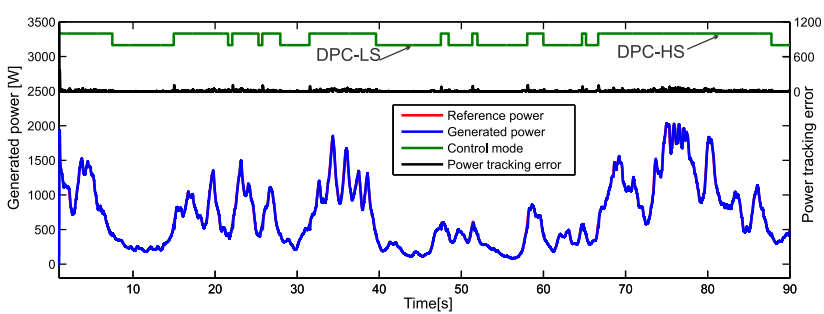

(c)

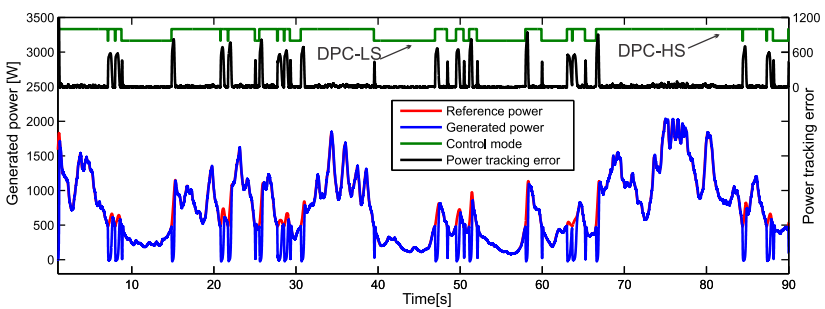

(d)

Fig. 20. Variable wind speed test. (a) Wind speed. (b) Mechanical speed and pitch angle. (c) Reference power, generated power, and power traking error (d) Results of commutation system without hysteresis and the use of initial feedback during systems switching.

where $K_{f}$ and $T_{f s}$ are gain and time constant of the filter, respectively.

A generic equation is used to model $C_{p}(\lambda, \beta)$. This equation, based on the modeling turbine characteristics of [1], is

$$
C_{p}(\lambda, \beta)=c_{1}\left(c_{2} / \lambda_{i}-c_{3} \frac{1}{\lambda_{i}} c_{4}\right) e^{-c_{5} / \lambda_{i}}+c_{6} \lambda
$$

with

$$
\frac{1}{\lambda_{i}}=\frac{1}{\lambda+0.08 \beta}-\frac{0.035}{\beta^{3}+1} .
$$

The coefficients $c_{1}$ to $c_{6}$ are: $c_{1}=0.5176, c_{2}=116, c_{3}=0.4$, $c_{4}=5, c_{5}=21$, and $c_{6}=0.0068$.

As shown in Fig. 19, the turbine torque $T_{T}$ is calculated from the wind speed and the wind turbine static characteristic block. Hence, the turbine torque is subtracted by the generator torque and the mechanical speed is calculated in the wind turbine dynamics block. The pitch angle control is implemented 


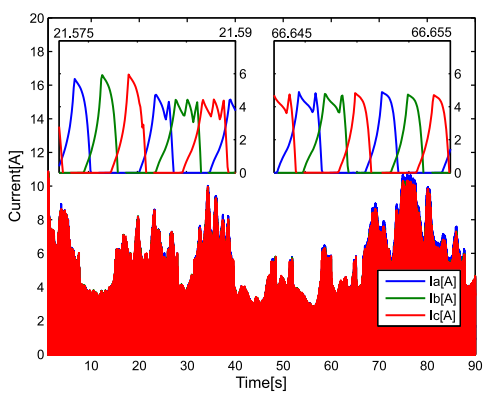

(a)

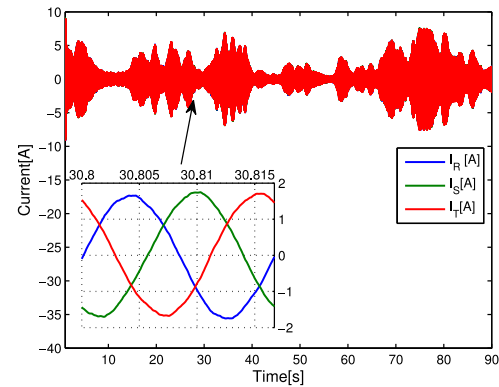

(d)

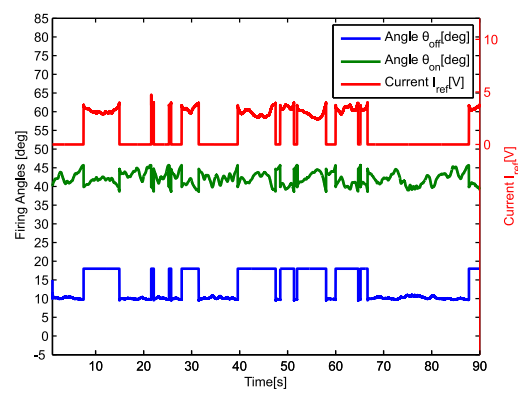

(b)

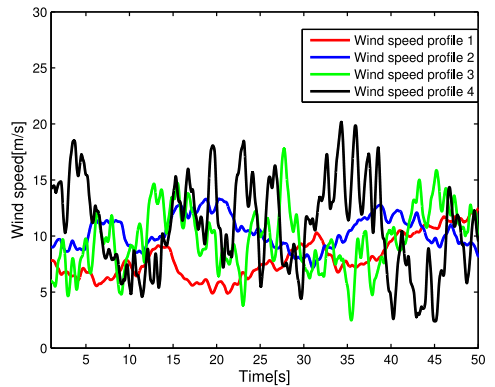

(e)

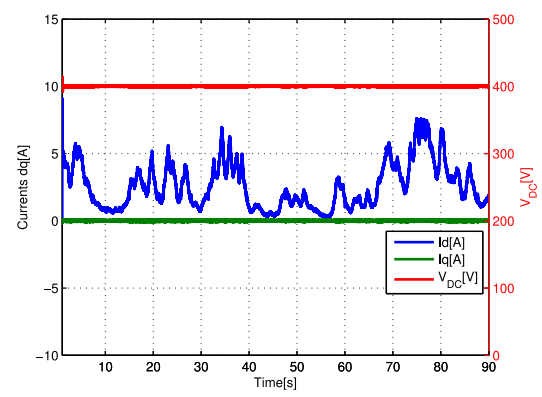

(c)

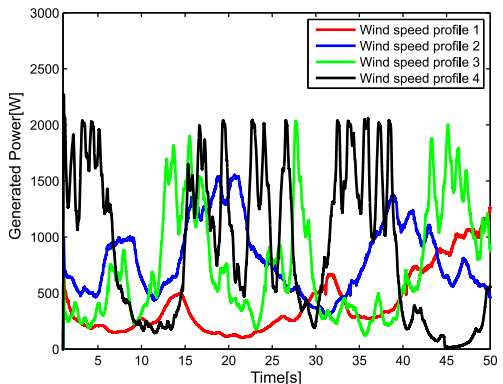

(f)

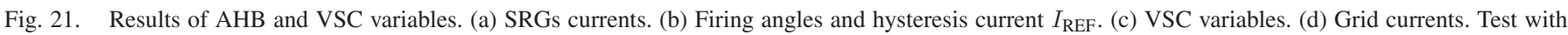
variable wind speed profiles. (e) Variable wind speed. (f) Generated power.

by a proportional error controller with limited pitch rate variability. For speeds below $w_{\max }$, the pitch angle is zero. The mechanical speed is used by the DPC control to calculate the power reference. Table II shows the data of the wind turbine simulation.

A 90 -s simulation was performed to test the system performance. Similar to the procedure performed in [1], a wind profile with high-frequency turbulence was emulated to test the robustness of the proposed system. The effects of the wind turbulence were increased using a very low inertia of $0.1 \mathrm{~kg} \cdot \mathrm{m}^{2}$. Fig. 20(a) presents the wind speed during the simulation. Fig. 20(b) shows the rotational speed, which has large variation because of low inertia consideration. The speed variation obtained was 60 $157 \mathrm{rad} / \mathrm{s}(572-1500 \mathrm{r} / \mathrm{min})$. The pitch angle control acted at $70 \mathrm{~s}$ of simulation, close to the maximum speed.

Fig. 20(c) shows the reference power and the generated power. The effectiveness of the proposed power controls is observed even during the switching of the controls. The obtained power tracking error is ever smaller than $\pm 24 \mathrm{~W}$ ( $1,2 \%$ of nominal power). Fig. 20(c) shows the results of the commutation system without hysteresis and the use of initial feedback during systems switching. In this case, a high power tracking error was verified during DPC's commutations. Besides, without hysteresis in the commutation systems, a higher number of fast transitions occurred, which causes abrupt variations in power generated during system switching and mechanical damage to the turbine.

The SRG currents at the time of switching between DPC modes can be seen in Fig. 21(a). Fig. 21(b) shows the SRG drives variables during the simulation. The firing angles $\left(\theta_{\text {on }}, \theta_{\text {off }}\right)$ were adjusted according to the control mode and operating speed to obtain the optimal conditions. In DPC-LS, the hysteresis current $I_{\text {ref }}$ is varied to control the power generated. These results show that it is possible to adjust the firing angles for optimizing values without causing problem in the generated power. Fig. 21(c) and (d) shows the VSC's variables. The dc-link voltage was controlled with good regulation even with variation in power generated. The reactive power is set to zero $(i q=0)$. A good power quality of the three-phase currents sent to the electrical grid was obtained, the THD was always less than $4 \%$. To test the robustness of the proposed system, various wind profiles were simulated [see Fig. 21(e)]. Fig. 21(f) shows the obtained results. In all wind profiles, the proposed control systems capture the optimal power with good performance.

\section{CONCLUSION}

The proposed structure to use SRG in a variable speed wind generation system was verified. Two DPCs were proposed, one by hysteresis of the SRG phase current for low-speed operation and second by a single pulse of current for high-speed operation. To improve the performance, the DPCs were tested with PI controllers and with SM controllers. SM controllers presented better results than PI controller. For operation throughout a wide speed range, the DPC-LS and DPC-HS controls should be joined by a commutative system. The results for the tests performed show that commutation of the DPCs occurred with a smooth transition, avoiding mechanical damage to the generator and allowing the SRG to operate over a wide range of speed variations. Thus, more mechanical energy can be captured in the wind generation. It was observed that the SRG can operate in a self-excited mode using a common dc bus system of a VSC connected to an electrical grid. Results of tests confirm the feasibility of using the proposed structure to send energy generated by the SRG to the electrical grid. 


\section{APPENDIX}

Parameters of the switched reluctance generator: $P_{n}=$ $2.0 \mathrm{~kW} ; V_{n}=300-450 \mathrm{~V} ; w_{n}=1500 \mathrm{r} / \mathrm{min} ; \frac{N_{s}}{N_{r}}=\frac{12}{8}$; $R_{s}=4.52 \Omega$.

TABLE II

DATA OF THE Wind TURBINE SiMULATION

\begin{tabular}{llc}
\hline \hline Parameter & \multicolumn{1}{c}{ Description } & Value \\
\hline$P_{\text {rated }}$ & Rated power & $2 \mathrm{~kW}$ \\
$k_{\text {opt }}$ & Wind turbine power coefficient & $5.16 \times 10^{4}$ \\
$w_{\text {rated }}$ & Rotational speed rated & $157 \mathrm{rad} / \mathrm{s}$ \\
$v_{w-\text { rated }}$ & Rated wind speed & $14.3 \mathrm{~m} / \mathrm{s}$ \\
$\rho$ & Air density & $1.225 \mathrm{~kg} / \mathrm{m}^{3}$ \\
$K_{f}$ & Gain of Karman filter & 200 \\
$T_{f s}$ & Constant time of Karman filter & $3.55 \times 10^{3}$ \\
\hline \hline
\end{tabular}

TABLE III

PARAMETERS OF SIMULATIONS AND EXPERIMENTS

\begin{tabular}{lcccc}
\hline \hline Control & Parameters & Value & Parameters & Value \\
\hline DPC-LS-PI & $K$ pbv & 0.002 & $K$ ibv & 0.04 \\
DPC-HS-PI & $K$ pav & 0.01 & $K$ iav & 0.02 \\
& $G i$ & $1 / 2000$ & $K d$ & 0.01 \\
& $\lim _{\text {int }}$ & +-100 & $K_{\text {psm }}$ & 0.1 \\
DPC-LS-SM & $K_{\text {ism }}$ & 20 & $G_{\text {eval }}$ & 10 \\
& $\operatorname{Lim}_{\text {eval }}$ & 15 & & \\
& $G i_{a v}$ & $1 / 2000$ & $K d_{a v}$ & 0.01 \\
& $\lim _{\text {int }}$ & \pm 100 & $K_{p i}$ & 0.1 \\
DPC-HS-SM & $K_{\text {piav }}$ & 20 & $G_{\text {evalav }}$ & 4 \\
& Lim $_{\text {evalav }}$ & 15 & & \\
$K_{d}(s), K_{q}(s)$ & $K$ pvsc & 10 & $K$ ivsc & 150 \\
$K_{v}(s)$ & $-n_{0}$ & -6.08 & $p$ & 1216 \\
\hline \hline
\end{tabular}

\section{REFERENCES}

[1] R. Cardenas, R. Pena, M. Perez, J. C. G. Asher, and P. Wheeler, "Control of a switched reluctance generator for variable-speed wind energy applications," IEEE Trans. Energy Convers., vol. 20, no. 4, pp. 691-703, Dec. 2005.

[2] D. Torrey, "Switched reluctance generators and their control," IEEE Trans. Ind. Electron., vol. 49, no. 1, pp. 3-14, Feb. 2002.

[3] R. Krishnan, Switched Reluctance Motor Drives: Modeling, Simulation, Analysis, Design, and Applications. Boca Raton, FL, USA: CRC Press, 2001.

[4] H. Chen and J. Gu, "Implementation of the three-phase switched reluctance machine system for motors and generators," IEEE/ASME Trans. Mechatronics, vol. 15, no. 3, pp. 421-432, Jun. 2010.

[5] C. E. Capovilla, I. R. S. Casella, A. J. S. Filho, T. A. dos S. Barros, and E. Ruppert, "Performance of a direct power control system using coded wireless OFDM power reference transmissions for SRG aerogenerators in a smart grid scenario," IEEE Trans. Ind. Electron., vol. 62, no. 1, pp. 52-61, Jan. 2015.

[6] V. Nasirian, S. Kaboli, A. Davoudi, and S. Moayedi, "High-fidelity magnetic characterization and analytical model development for switched reluctance machines," IEEE Trans. Magn., vol. 49, no. 4, pp. 1505-1515, Apr. 2013.

[7] T. S. Barros and E. Ruppert, "Direct power control for switched reluctance. generator in wind energy," Latin Amer. Trans., vol. 13, no. 1, pp. 123-128, Jan. 2015

[8] Y. T. Chang and K. Cheng, "Sensorless position estimation of switched reluctance motor at startup using quadratic polynomial regression," IET Electr. Power Appl., vol. 7, no. 7, pp. 618-626, Aug. 2013.

[9] H. U. Shin, K. Park, and K. B. Lee, "A non-unity torque sharing function for torque ripple minimization of switched reluctance generators in wind power systems," Energies, vol. 8, no. 10, pp. 11685-11701, 2015.
[10] V. P. Vujicic and M. P. Calasan, "Simple sensorless control for highspeed operation of switched reluctance generator," IEEE Trans. Energy Convers., vol. 31, no. 4, pp. 1325-1335, Dec. 2016.

[11] D. W. Choi, S. Byun, and Y. Cho, "A study on the maximum power control method of switched reluctance generator for wind turbine," IEEE Trans. Magn., vol. 50, no. 1, Jan. 2014, Art. no. 4003004.

[12] A. Labak and N. Kar, "Designing and prototyping a novel five-phase pancake-shaped axial-flux SRM for electric vehicle application through dynamic FEA incorporating flux-tube modeling," IEEE Trans. Ind. Appl., vol. 49, no. 3, pp. 1276-1288, May 2013.

[13] P. Lobato, J. Martins, and A. J. Pires, "Scale models formulation of switched reluctance generators for low speed energy converters," IET Electr. Power Appl., vol. 9, no. 9, pp. 652-659, 2015.

[14] J. H. Oh and B. I. Kwon, "Design, optimization, and prototyping of a transverse flux-type-switched reluctance generator with an integrated rotor," IEEE Trans. Energy Convers., vol. 31, no. 4 pp. 1521-1529, Dec. 2016.

[15] H. U. Shin and K. B. Lee, "Optimal design of a $1 \mathrm{kw}$ switched reluctance generator for wind power systems using a genetic algorithm," IET Electr. Power Appl., vol. 10, no. 8, pp. 807-817, 2016.

[16] Y. Bao, K. Cheng, X. Xue, J. Chan, Z. Zhang, and J. Lin, "Research on a novel switched reluctance generator for wind power generation," in Proc. 4th Int. Conf. Power Electron. Syst. Appl., Jun. 2011, pp. 1-6.

[17] X. Xue, K. Cheng, Y. Bao, P. Leung, and N. Cheung, "Switched reluctance generators with hybrid magnetic paths for wind power generation," IEEE Trans. Magn., vol. 48, no. 11, pp. 3863-3866, Nov. 2012.

[18] X. Liu and K.Park, and Z. Chen, "A novel excitation assistance switched reluctance wind power generator," IEEE Trans. Magn., vol. 50, no. 11, pp. 1-4, Nov. 2014.

[19] T. Sawata, "The switched reluctance generator," in Electronic Control of Switched Reluctance Machines (Newness Engineering Series). Amsterdam, The Netherlands: Elsevier, 2001

[20] A. M. Iturbe, F. J. P. Cebolla, B. Martín, C. Bernal, and A. B. Nuez, "Energy transformations in a self-excited switched reluctance generator," Energies, vol. 9, no. 5, 2016, Art. no. 321.

[21] C. R. D. Osorio, R. P. Vieira, and H. A. Grundling, "Sliding mode technique applied to output voltage control of the switched reluctance generator," in Proc. 42nd Annu. Conf. IEEE Ind. Electron. Soc., Oct. 2016, pp. 2935-2940.

[22] K. Hu, J. C. Wang, T. S. Lin, and C. M. Liaw, "A switched-reluctance generator with interleaved interface dc converter," IEEE Trans. Energy Convers., vol. 30, no. 1, pp. 273-284, Mar. 2015.

[23] V. B. Koreboina and L. Venkatesha, "Modelling and simulation of switched reluctance generator control for variable speed wind energy conversion systems," in Proc. IEEE Int. Conf. Power Electron. Drives Energy Syst., 2012, pp. 1-6.

[24] K. Park and Z. Chen, "Self-tuning fuzzy logic control of a switched reluctance generator for wind energy applications," in Proc. 3rd IEEE Int. Symp. Power Electron. Distrib. Gener. Syst., Jun. 2012, pp. 357-363.

[25] M. Eddine, M. Imed, F. Mourad, and R. Habib, "Modeling and control of a switched reluctance machine for wind generation," in Proc. Int. Conf. Elect. Eng. Softw. Appl., Mar. 2013, pp. 1-5.

[26] Z. Huang, J. Wan, and J. Xiao, "Research on SRG wind power system based on MPPT control scheme," in Proc. Int. Conf. Elect. Eng. Mechatronic Sci., Dec. 2013, pp. 3248-3252.

[27] M. P. Ćalasan and V. P. Vujičić, "A robust continuous conduction mode control strategy of switched reluctance generator for wind power plant applications," Elect. Eng., vol. 99, pp. 1-16, 2016.

[28] H. M. Hasanien and S. Muyeen, "Speed control of grid-connected switched reluctance generator driven by variable speed wind turbine using adaptive neural network controller," Electr. Power Syst. Res., vol. 84, no. 1, pp. 206-213, 2012.

[29] S. M. Muyeen, A. Al-Durra, and H. M. Hasanien, "Application of an adaptive neuro-fuzzy controller for speed control of switched reluctance generator driven by variable speed wind turbine," in Proc. 2015 Mod. Electr. Power Syst., Jul. 2015, pp. 1-6.

[30] D. McSwiggan, L. Xu, and T. Littler, "Modelling and control of a variablespeed switched reluctance generator based wind turbine," Proc. 42nd Universities Power Eng. Conf., Jun. 2007, pp. 459-463.

[31] G. Viajante et al., "A grid connection scheme of a switched reluctance generator for active power injection," in Proc. IEEE Int. Elect. Mach. Drives Conf., May 2013, pp. 415-420.

[32] Y. C. Chang, C. H. Cheng, L. Y. Lu, and C. M. Liaw, "An experimental switched-reluctance generator based distributed power system," in Proc. 19th Int. Conf. Elect. Mach., Sep. 2010, pp. 1-6. 
[33] G. Viajante et al., "A grid connection scheme of a switched reluctance generator for active power injection using p-resonant (p-res) controller," Electr. Power Syst. Res., vol. 141, pp. 572-579, 2016.

[34] G. P. Viajante et al., "Switched reluctance generator in connection with the three-phase power grid," in Proc. IEEE 15th Int. Conf. Environ. Elect. Eng., Jun. 2015, pp. 1527-1532.

[35] Y. Sozer and D. Torrey, "Closed loop control of excitation parameters for high speed switched-reluctance generators," IEEE Trans. Power Electron., vol. 19, no. 2, pp. 355-362, Mar. 2004.

[36] V. Nasirian, S. Kaboli, and A. Davoudi, "Output power maximization and optimal symmetric freewheeling excitation for switched reluctance generators," IEEE Trans. Ind. Appl., vol. 49, no. 3, pp. 1031-1042, May/Jun. 2013.

[37] I. Kioskeridis and C. Mademlis, "Optimal efficiency control of switched reluctance generators," IEEE Trans. Power Electron., vol. 21, no. 4, pp. 1062-1071, Apr. 2006.

[38] Y.-C. Chang and C.-M. Liaw, "Establishment of a switched-reluctance generator-based common dc microgrid system," IEEE Trans. Power Electron., vol. 26, no. 9, pp. 2512-2527, Sep. 2011.

[39] P. Asadi, M. Ehsani, and B. Fahimi, "Design and control characterization of switched reluctance generator for maximum output power," in Proc. Appl. Power Electron. Conf. Expo., Mar. 2006, pp. 1639-1644.

[40] T. A. Barros, P. J. Neto, P. S. Filho, A. B. Moreira, and E. Ruppert, "Approach for performance optimization of switched reluctance generator in variable-speed wind generation system," Renewable Energy, vol. 97, pp. 114-128, 2016.

[41] K. Ogata, Modern Control Engineering. Upper Saddle River, NJ, USA: Prentice-Hall, 2000.

[42] C. Lascu, I. Boldea, and F. Blaabjerg, "Direct torque control of sensorless induction motor drives: A sliding-mode approach," IEEE Trans. Ind. Appl., vol. 40, no. 2, pp. 582-590, Mar. 2004.

[43] J. Hung and J. Hung, "Variable structure control: A survey," IEEE Trans. Ind. Electron., vol. 40, no. 1, pp. 2-22, Feb. 1993.

[44] V. Utkin, Sliding Modes in Control and Optimization. New York, NY, USA: Springer-Verlag, 1992.

[45] V. Utkin, J. Guldner, and J. Shi, Sliding Mode Control in ElectroMechanical Systems, 2nd ed. Boca Raton, FL, USA: CRC Press, 2009.

[46] A. Yazdani and R. Iravani, Voltage-Sourced Converters in Power Systems: Modeling, Control, and Applications. New York, NY, USA: Wiley-IEEE Press, 2010.

[47] A. Berzoy, A. Elsayed, T. Youssef, and O. A. Mohammed, "Improved design of controlled rectifier for reduced ripple resulting from integration of dc loads to ac systems," in Proc. 2014 IEEE PES Gen. Meeting Conf. Expo., Jul. 2014, pp. 1-5.

[48] J. Muhlethaler, M. Schweizer, R. Blattmann, J. W. Kolar, and A. Ecklebe, "Optimal design of LCL harmonic filters for three-phase PFC rectifiers," IEEE Trans. Power Electron., vol. 28, no. 7, pp. 3114-3125, Jul. 2013.

[49] R. Teichmann, M. Malinowski, and S. Bernet, "Evaluation of three-level rectifiers for low-voltage utility applications," IEEE Trans. Ind. Electron., vol. 52, no. 2, pp. 471-481, Apr. 2005.

[50] B. Karanayil, V. G. Agelidis, and J. Pou, "Performance evaluation of three-phase grid-connected photovoltaic inverters using electrolytic or polypropylene film capacitors," IEEE Trans. Sustain. Energy, vol. 5, no. 4, pp. 1297-1306, Oct. 2014.

[51] G. Henz, G. Koch, C. Franchi, and H. Pinheiro, "Development of a variable speed wind turbine emulator for research and training," in Proc. Brazilian Power Electron. Conf., Oct. 2013, pp. 737-742.

[52] C. Nichita, B. Luca, and E. Ceanga, "Large band simulation of the wind speed for real time wind turbine simulators," IEEE Trans. Energy Convers., vol. 17, no. 4, pp. 523-529, Dec. 2002.

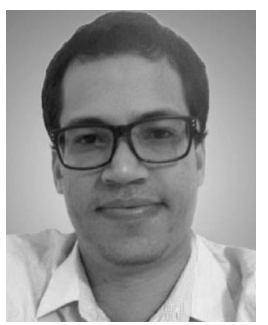

Tárcio André dos Santos Barros (S'14-M'17) was born in Petrolina, Brazil, on September 19, 1987. He received the Bachelor's degree in electrical engineering from the Federal University of Vale do São Francisco, Petrolina, in 2010, and the M.S. and Ph.D. degrees from the University of Campinas, Campinas, Brazil, in 2012 and 2015, respectively.

From 2016 to 2017, he was a Researcher with the University of Campinas, under the FAPESP Postdoctoral Program. He is currently a Professor with the University of Campinas. He works in the areas of electrical machines, power electronics, and electrical drives. His research interests include machine drives, switched reluctance machines, doubly fed induction generators, and solar energy. He is a member of the PELS and Brazilian Society of Power Electronics.

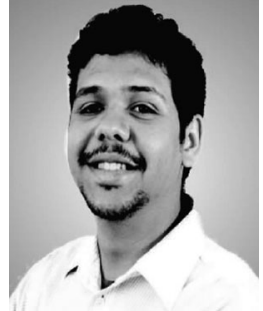

Pedro José dos Santos Neto (S'15) was born in Petrolina, Brazil, on October 12, 1991. He received the bachelor's degree in electrical engineering from the Federal University of Vale do São Francisco, Petrolina, in 2016. He is currently working toward the M.S. degree from the University of Campinas, Campinas, Brazil.

He works in the areas of electrical machines, power electronics, and electrical drives. His research interests include renewable energy, distributed generation, switched reluctance machines, and permanent magnet synchronous generator.

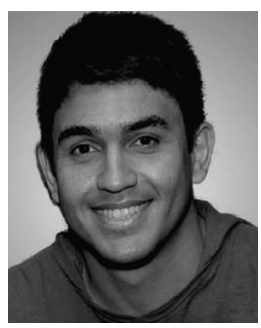

Paulo Sergio Nascimento Filho received the Graduate degree in electrical engineering, in 2009, and the master's degree in electrical engineering, in 2011, from the Federal University of Pará, Belém, Brazil, where he researched the control of dynamical systems applied in electric power generation systems with the highlight for speed controllers of hydraulic turbines and thermal turbines, voltage regulators of synchronous generators, and power stabilizers system. He received the Doctoral degree in electrical engineering in 2017 from the State University of Campinas, Campinas, Brazil, with a scholarship from $\mathrm{CNPq}$, where he researched advanced control strategies and power electronics applied to power systems and distributed generation

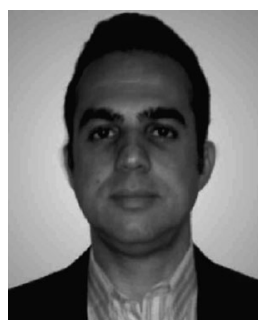

Adson Bezerra Moreira (M'17) was born in Fortaleza, Ceará, in 1979. He received the B.Sc. and M.Sc. degrees in electrical engineering, both from the Federal University of Ceará (UFC), Fortaleza, in 2003 and 2006, respectively. He is currently working toward the Doctoral degree at the University of Campinas, Campinas, Brazil.

Since 2008, he has been at UFC, Sobral, Brazil, where he is an Assistant Professor. His research interests include energy efficiency, power quality, electric machine drives, and power generation.

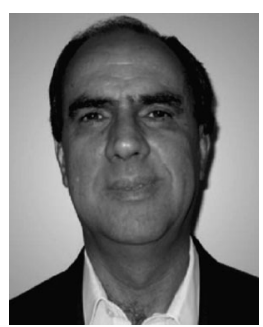

Ernesto Ruppert Filho (M'00) received the B.S. degree in electrical engineering and the M.S. and Ph.D. degrees in electrical engineering from the University of Campinas (UNICAMP), Campinas, Brazil, in 1971, 1974, and 1983, respectively.

From 1972 to 1978 , he was with the Electrical and Computer Engineering School, UNICAMP, as an Assistant Professor of electromechanical energy conversion. From 1979 to 1983 , he was with General Electric, Brazil, designing large induction and synchronous motors and working as an Application Engineer dedicated to large motors and generators. From 1983 to 1989 , he was with Vigesa Heavy Equipment, Brazil, designing very large hydrogenerators and also performing commissioning tests on hydropower plants in Brazil. He is currently a Full Professor with the Electrical and Computer Engineering School, UNICAMP, researching and teaching in the areas of electrical machines, power electronics, drives, and electrical power systems. 